\title{
Heterogeneity in biomarkers, mitogenome and genetic disorders of the Arab population with special emphasis on large-scale whole-exome sequencing
}

\author{
J. Francis Borgio
}

Department of Genetic Research, Institute for Research and Medical Consultations (IRMC), Imam Abdulrahman Bin Faisal University, Dammam, Saudi Arabia

Submitted: 15 October 2021; Accepted: 27 December 2021 Online publication: 27 December 2021

Arch Med Sci

DOI: https://doi.org/10.5114/aoms/145370

Copyright @ 2021 Termedia \& Banach

\section{Abstract}

More than 25 million DNA variations have been discovered as novel including major alleles from the Arab population. Exome studies on the Saudi genome discovered > 3000 novel nucleotide variants associated with > 1200 rare genetic disorders. Reclassification of many pathogenic variants in the Human Gene Mutation Database and ClinVar Database as benign through the Arab database facilitates building a detailed and comprehensive map of the human morbid genome. Intellectual disability comes first with the combined and observed carrier frequency of 0.06779 among Saudi Arabians; retinal dystrophy is the next highest. Genome studies have discovered interesting novel candidate disease marker variations in many genes from consanguineous families. More than 7 pathogenic variants in the C12orf57 gene are prominently associated with the etiology of developmental delay/ intellectual impairment in Arab ancestries. Advances in large-scale genome studies open a new outlook on Mendelian genes and disorders. In the past half-dozen years, candidate genes of intellectual disability, neurogenetic disorders, blood and bleeding disorders and rare genetic diseases have been well documented through genomic medicine studies in combination with advanced computational biology applications. The Arab mitogenome exposed hundreds of variations in the mtDNA genome and ancestral sharing with Africa, the Near East and East Asia and its association with obesity. These recent discoveries in disease markers and molecular genetics of the Arab population will have a positive impact towards supporting genetic counsellors on reaching consanguineous families to manage stress linked to genetics and precision medicine. This narrative review summarizes the advances in molecular medical genetics and recent discoveries on pathogenic variants. Despite the fact that these initiatives are targeting the genetics and genomics of disorders prevalent in Arab populations, a lack of complete cooperation across the projects needed to be revisited to uncover the Arab population's prominent disease markers. This shows that further study is needed in genomics to fully comprehend the molecular abnormalities and associated pathogenesis that cause inherited disorders in Arab ancestries.

Key words: Arab world, Mendelian genes, intellectual disability, medical genetics, genetic disorders, pathogenic mutation, exome.

\section{Introduction}

The Arab population or people speaking the Arabic language are reported to have a significantly high incidence of genetic abnormalities due

\author{
Corresponding author: \\ J. Francis Borgio, PhD, \\ Assoc. Prof. \\ Department of Genetic \\ Research \\ Institute for Research and \\ Medical Consultations (IRMC) \\ Imam Abdulrahman \\ Bin Faisal University \\ Dammam 31441, \\ Saudi Arabia \\ Phone: 00966133330864. \\ E-mail: \\ fbalexander@iau.edu.sa, \\ borgiomicro@gmail.com
}


to the high rate of first-cousin marriages [1]. Increased level of inbreeding, large family sizes, and high mother and father ages characterize the Arab population. In earlier days not much familiar public health effort was aimed at preventing genetic diseases, but recently country-wide initiatives for screening and preventive measures have been initiated. In the recent past, many genetic disorders have received attention in the field of medical genetics to identify disease-causing mutations using next-generation sequencing techniques in the Arab region. Vast deserts, suffocating heat, oil wells, throngs of pilgrims, and prosperous-looking cities continue to dominate popular opinions of the Arab population, especially Saudi Arabia. This view is now expanded to incorporate an advanced initiative that is claiming a global spotlight as one of the top human genomics projects: the Saudi Human Genome Program (SHGP), Kuwait Genome Project (KGP), Qatar Genome Programme (QGP), Emirati Genome Program (EGP), and Bahrain Genome Project (BGP). Arab countries such as the Kingdom of Saudi Arabia, United Arab Emirates and Qatar have invested a lot of money and efforts in next-generation genomics to reveal the molecular basis of diseases and disorders prevalent in the Arab population. The post-Arab genome programs are a golden era in molecular genetics and disease biomarkers of Arabian genomic studies. These Arab genome programs have overcome the obstacles and limitations of collecting samples. The SHGP, KGP, QGP, EGP and BGP programs are visionary projects on human genomics with the vision to detect and prevent genetic diseases in the Kingdom of Saudi Arabia (KSA), the State of Kuwait, the State of Qatar, the United Arab Emirates (UAE) and the Kingdom of Bahrain, to establish world-class facilities in genomic research in the Arab ancestry [2-6]. The SHGP was implemented by King Abdulaziz City for Science and Technology, on its way to sequence 100,000 human genomes in Saudi Land to achieve gold standard findings in the Saudi population on genomics-based biomedical research [2]. The central laboratory of SHGP in 2018 is one of the first national initiatives and the largest genomic project in the Middle East; details can be obtained from the freely available database (https://shgp.kacst.edu.sa/index.en.html) [7]. The SHGP initiative revealed > 3000 new nucleotide variants to the literature, that are associated with $>1200$ rare genetic disorders [7-9]. Earlier reviews on population structure and prevalent genetic disorders can help to understand the initial studies on Mendelian genes and associated traditions in the high consanguineous community of the Kingdom of Saudi Arabia and other Arab populations [10-12]. The State of Qatar, which is located in the Arabian Gulf, established the QGP (https://www. qatargenome.org.qa/), a Qatari population-based genome initiative aimed at sequencing the complete genomes of a large part of the Qatari population, which began its pilot phase in 2015 [3]. The Kuwait Genome Project (KGP) is a high-coverage effort to sequence Kuwaiti genomes from genetically different subgroups of Kuwaitis [4].

Although genome research has the potential to transform medical approaches related to prevention of disorders, developing advanced diagnosis, and formulating treatment strategies, it is not without its obstacles and limitations [3]. The willingness of individuals to volunteer samples and use genetic testing services is critical to achieve the goals of the national genome initiatives like KGP, SHGP, QGP, BGP and EGP. Basic genetic knowledge, a genetic history of families with genetic disorders, and prior experience were all found to be significant predictors of willingness of Arabs to participate. The findings from 837 adult Qataris show widespread acceptance, but the study also points to the need for greater education and personalized counselling to explain the procedure, obstacles, and advantages of genetic testing [3]. These Arab genome initiatives have surmounted the challenges and constraints of sample collection. Whole exome sequencing (WES) on evaluating 48 Qatari (30 families) patients with inherited Mendelian disorders from the "Qatar Mendelian Disease pilot program", revealed 25 unique disease-causing pathogenic alleles that are important to premarital and newborn screening of Arab populations [13]. Next-generation sequencing methods such as WES play an important role in molecular pathogenesis $[14,15]$. The narrative review reviews the advances throughout the Arab genome program period, including major breakthroughs in pathogenic disease-associated variations and advances in molecular genetics from large-scale whole-exome sequencing data.

\section{Novel variants and reclassifying pathogenic variants as benign}

The initial study on Qataris revealed 58.37\% novel variants among the identified 5,452,613 variants [16]. Significant differences were observed in the initial studies on the Saudi genome [17], and Kuwaiti genome [4, 18]. Still more indepth genome-wide studies are needed [19]. Recent findings from QGP phase 1 , which sequenced the whole genomes of 6,045 Qataris, were reported. They found almost 88 million DNA variations, interestingly, with $24,620,313$ of them being novel to various genome databases [20]. The study discovered that many uncommon deletion variations were more common and prevalent in the Qatari population. Most of the observed novel variants appear to give disease protection in the Qatari 
population and have changed the genetic architecture, which is consistent with the region's high consanguinity. Five non-admixed groupings were discovered in the genetic makeup of the Qatari population. The study also described the heritability of genetic disease marker correlations for 45 clinical phenotypes [20]. A recent study on reclassification of pathogenic variants (16 Human Gene Mutation Database (1 disease mutation and 15 disease mutations) variants and 10 ClinVar (6 pathogenic, 4 variants of uncertain significance) variants) as benign by the team of the Saudi Human Genome Program (SHGP) database was possible because of the world's biggest collection of genetic variations from Arabs through the establishment of the SHGP database [8]. The SHGP database using 3070 disease-associated genes (including 2000 whole-exome sequencing WES) covering > 4000 Mendelian disorders of 5849 non-overlapping individuals can reveal Arab-enriched and Arab-specific common variants in the Arab population in general and the Saudi population in particular [8]. It was expected that at least some reported "genetic disease-associated variants" might characterize Arab-enriched or Arab-specific common mutations that might not be detected as such by utilizing these genomic data as most of the disease-associated genes and variants were described for the first time in Arab subjects with disease phenotype due to the high level of consanguinity. Also these factors enable positional mapping in the genome, since ethnicity is not much represented in publicly accessible variant databases (Figure 1). The study revealed that 16 HGMD variants and 10 ClinVar variants had a Saudi ancestry frequency (in population) of 5\% in the database (SHGP) but only $<5 \%$ in publicly available databases, allowing all these 26 pathogenic variants to be reliably reclassified as benign. Autozygosity is rich in the SHGP database; based on Saudi population frequency (> 1\%) and occurrence of genotype homozygosity in Saudi individuals who lack the phenotype described already, the study was able to reclassify 484 ClinVar variants (184 pathogenic, 25 likely pathogenic, 275 variant of uncertain significance) and 607 HGMD variants (103 disease mutation and 504 disease mutation) as benign [8]. Due to the founder effect, QGP revealed certain rare pathogenic variant mutations with high MAF in the Qatari population [20]. Variant rs750046020 in the MPL gene, specifically linked with thrombocytosis, occurs with MAF of 0.009 in the Qatari Arab population [20]. Similarly, at an MAF of 0.007 , variations in the genes KRT5 (rs267607448) and CBS (rs398123151) linked to epidermolysis bullosa and homocystinuria, respectively, are found in the Qatari population [20]. Ten novel mutations were discovered in ten known genes associated with myeloproliferative neoplasms, and seven potential candidate genes

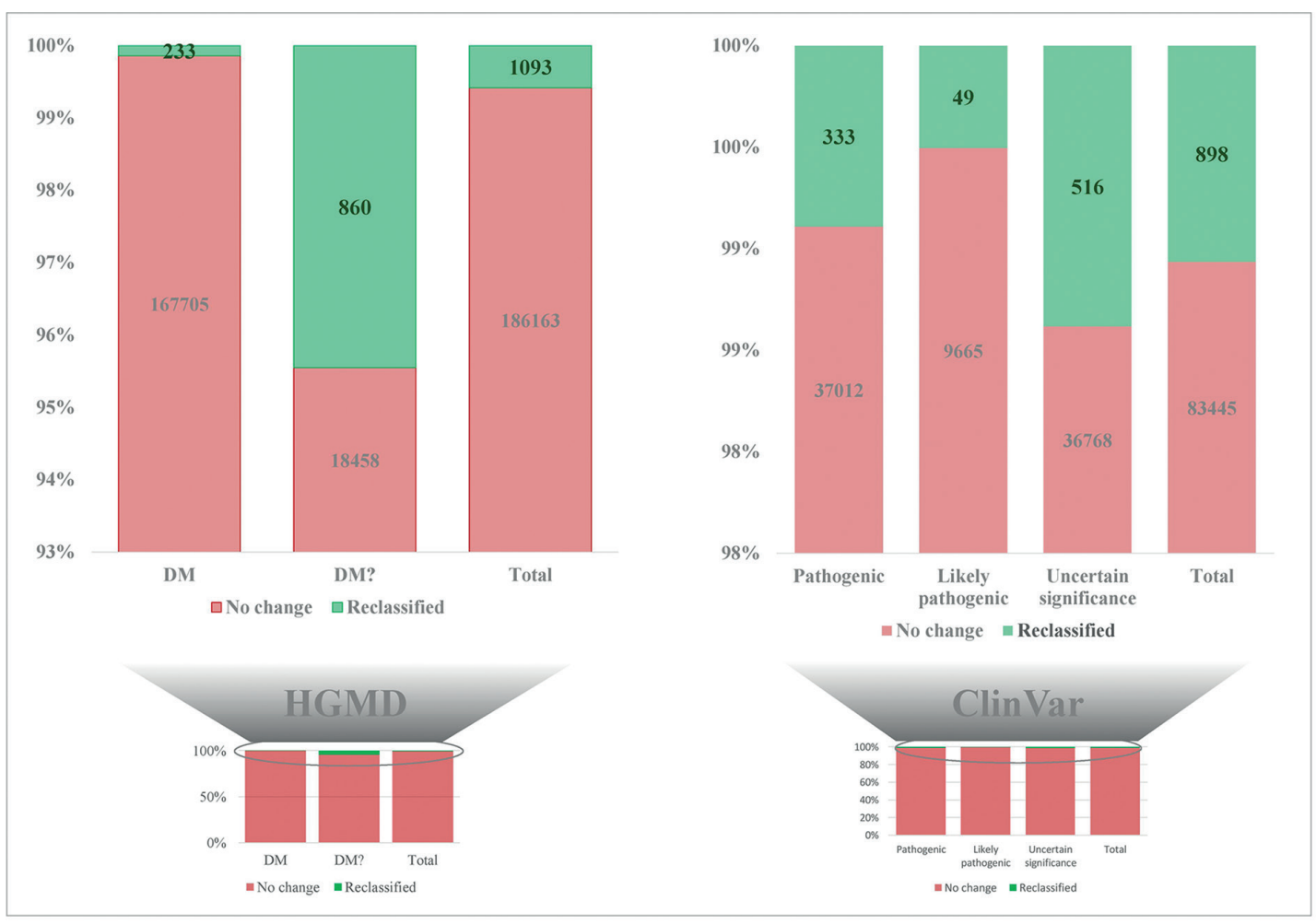

Figure 1. Reclassified variants in HGMD (Human Gene Mutation Database) and ClinVar Database through SHGP database observations 
were discovered with seven novel variants from Qatari patients with myeloproliferative neoplasms [21]. A total of 1,790,171 annotated variants and 8,462 structural variants, found as novel variations across the Emirati genome, were found while constructing the United Arab Emirates Reference Genome [22]. Kuwaiti genome studies discovered 58,186 SNPs, 32,686 indels as novel variants [4, 18]. Most of the coding novel variants discovered in the Kuwaiti genome studies were found to be associated with autosomal recessive disorders in the Arab population [18].

\section{Carrier frequency of genetic disorders}

The combined and observed carrier frequency of genetic disorders among Saudi Arabians was estimated for the first time by utilizing a large sample ( $n=7,101$ patients) using targeted gene panel sequencing and whole-exome sequencing [7]. The study revealed the most prevalent carrier status of various diseases (Figure 2): intellectual disability comes first with the combined and observed carrier frequency of 0.06779 , followed by retinal dystrophy, glaucoma, inborn errors of metabolism, sickle cell disease/thalassemia, deafness, dysmorphic/dysplasia, ataxia, myopathy/ muscular dystrophy, polycystic kidney disease/ nephronophthisis, Joubert syndrome/Meckel-Gruber syndrome, carbonic anhydrase II deficiency, cystic fibrosis, Bardet-Biedl syndrome, and cataract [7] (Figure 2). Furthermore, a study on 2357 Saudi patients through gene panels revealed 433 novel disease alleles and 355 existing variants, which is the largest notable number of novel disease alleles submitted to the HGMD in a single genomic study. Third, the 433 novel disease variants identified in the genome study by the Saudi Mendeliome Group represent an exceptional resource on the Arab variome (whole set of genetic variations) as most of the study participants were of Arab origin. Hence these observations and additions to the HGMD by the Saudi genome studies constitute an invaluable resource for the interpretation of clinical and molecular genomic analysis on Mendelian genes in Arab patients [23]. These

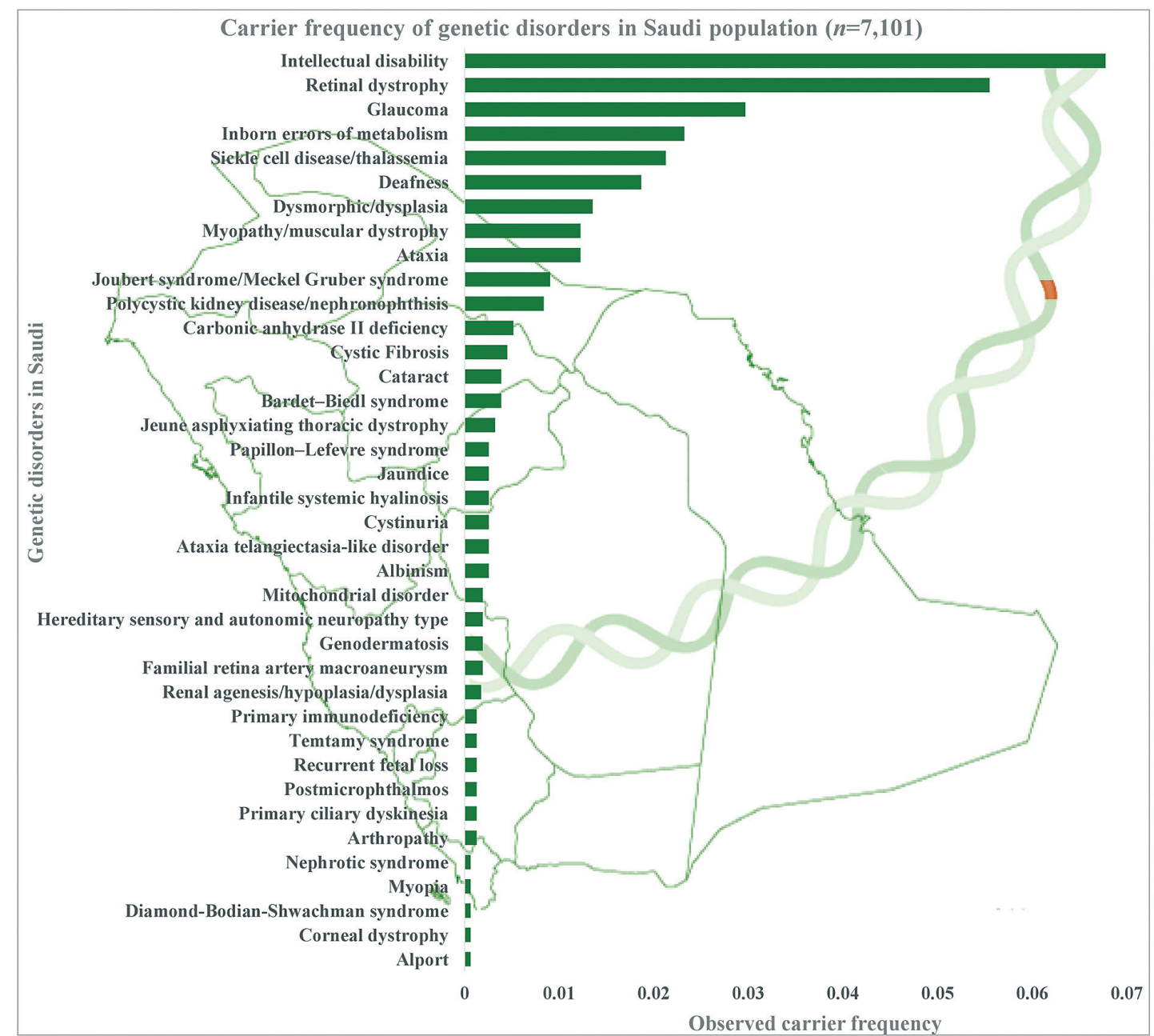

Figure 2. Combined and observed carrier frequency of genetic disorders in Arab ancestries with an example from Saudi Arabian population $(n=7,101)$ 
novel disease markers will help address the uncertainty in the identification of many Arab-specific disease markers. All these studies reveal a high prevalence of variants and carriers, as the degree of consanguinity is high among the Saudi ancestry; hence studies were able to identify a lot of autozygosity-related variations in homozygosity $[7,23]$. The large-scale exome studies on the carrier frequency of genetic disorders among the Arab population change the previous observations of the most prevalent hemoglobinopathies $[7,11]$. Carrier frequency of the intellectual disability is three times more than that of sickle cell disease and thalassemia among the Arab population with $25-60 \%$ consanguinity rates $[7,11]$. In-depth functional analysis of observed intellectual disability genetic markers can help in the early identification of intellectual disability genetic markers and designing novel treatment strategies. The most prevalent recessive alleles discovered in the $\mathrm{Qa}$ tari population are those associated with developmental disorders and structural deformities [20]. It is not surprising that the large number of Arabs in Saudi Arabia share similar and common carrier frequency with Qatar's native population with minor differences in some alleles (DCAF17: c.436delC) [20].

\section{Clinically relevant traits and precision medicine}

A foundation stone was laid in studies on the Qatari population on the clinically relevant traits and loci associated genetics along with earlier studies [16, 24]. Genetics has an important role in the output and diversity in the clinical laboratory test results and decision-making in precision medicine [24]. Furthermore, very little is known about the genetic variability of the Arab population compared to other ancestries. A detailed study presented the results of genome-wide association research on forty-five clinically relevant features among the Qatari population, conducted by means of WES technique of 6218 subjects $[24,25]$. They reported Arab (Qatari) and European populations with similar trait heritability $(r=$ 0.81). Moreover, Arab (Qatari) ancestries are less similar to African ancestries $(r=0.44)$ in trait heritability. The authors found 281 unique and significant associations between the variants and clinical traits through GWAS analysis, which coincide with previously discovered associations with other populations, mainly Europeans. The relationships between allele frequencies for repeated loci are lower in Japanese $(r=0.80)$ and African $(r=0.85)$ populations while being higher in European $(r=0.94)$ populations [26-29]. The authors presented 17 novel and Arab-dominant signals based on Qataris that shed light on the molecular pathways that control the clinical traits
[24]. The polygenic scores developed from European data have lower predictive performance in the Qatar-based Arab population. Findings from the large-scale analysis on the clinical traits of the Arab population are expected to have an impact on its future use in precision medicine and genetic architecture of complex diseases prevalent in the Arab population. Finally, for the first time in an Arab population, this study on heritability analysis and GWAS-based genetic association analysis on clinically relevant variables importantly identified shared genetic loci with variation in linkage disequilibrium patterns [24]. Metabolic quantitative trait loci identification analysis revealed genetic loci associated with pharmacological/drug targets on the consanguineous Arab population, which is important for precision medicine in the Arab world [30]. Constructing specific reference sequences for a subpopulation of Arab ancestry is also important in precision medicine; the initiation of the UAE reference panel is a good initiative [22, 31, 32].

\section{High genetic heterogeneity}

The Arab population is known for its high genetic heterogeneity in the diversity of phenotypes and clinical outcomes [1, 33-38]. The Arab world is an ethnocultural melting pot located geographically as a land bridging Eurasia and Africa, which functioned as a gateway for the migration of humans from the African region to the rest of the civilized world. The wide range of pathogenic gene mutations linked to various genetic diseases in the Arabs perhaps best exemplifies the heterogeneity of Arabs [1]. The high consanguinity of Arab people is well known. Because of the complexity of consanguinity and heterogeneity, understanding the causes of Arab population-specific genetic disorders in the region is challenging. The Arab region is populated by genetically diverse populations, as evidenced by previous genetic studies [ 1 , 33-36]. Inter-regional genetic variability in Arab ancestry is also highlighted in a recent GWAS study [36]. The prevalence of heterogeneity in genetics of highly consanguineous Arab families makes the interpretation for the genetic basis and etiology of numerous inherited disorders most common in Arab populations. In Arab countries, more than 1200 distinct genetic disorders have been documented, $60 \%$ of which are autosomal recessive disorders and more than $40 \%$ are confined to a certain demographic or geographical location [1, 10-12, 33]. High-resolution population genetic studies on the Arab population were carried out to understand the genetic diversity of inherited diseases and the degree of heterogeneity among Kuwaiti Arabs using SNP microarray $(n=$ 583) [1]. Within the newly established groupings, the study infers the primary sources of ancestry 
among Kuwaiti Arabs. Various findings reinforce the genetic imprints and regional genetic heterogeneity in Arab people on the blood disorders, metabolic disorders, disorders of the circulatory system, breast cancer, ovarian cancer, colorectal carcinoma and prostate cancer [1].

\section{Neurogenetic disorders and candidate genes}

The most common referral request for WES analysis was for neurological diseases in an Arab country (Lebanon) [39]. WES analysis of pre-screened multiplex consanguineous families with neurogenetic disorders revealed candidate genes and disease markers [40]. 33 genes (observed phenotype), i.e. SPDL 1 (primary microcephaly and neonatal death), TUBA3E (microlissencephaly and global developmental delay), INO80, TSEN15, and PCDHB4 (global developmental delay or GDD and primary microcephaly), DMBX1 (epilepsy, GDD, and poor weight gain), CLHC1 (myopathy), NID1 (muscle weakness, hydrocephalus, and global developmental delay), C12orf4 (global developmen- tal delay), WDR93 (autism spectrum disorder), ST7 (brain atrophy and global developmental delay), MATN4 (holoprosencephaly), SEC24D, and MYOCD (intellectual disability and epilepsy), KIAA1109 (Dandy-Walker malformation, club feet, flexed deformity, hydrocephalus, pleural effusion and micrognathia), PTPN23 (global developmental delay and brain atrophy), TAF6 (global developmental delay and dysmorphism), TBCK (hypotonia, GDD, dysmorphism, epilepsy, and VSD), FAM177A1 (macrocephaly, dolichocephaly, intellectual disability, and mild obesity), MTSS1L (neurodegeneration and brain iron accumulation), ARV 1 (neurodegenerative disease), XIRP1 (primary microcephaly), CHAF1B (global developmental delay and ADHD), KCTD3 (cerebellar hypoplasia, seizure, and severe psychomotor retardation), ISCA2 (consistent with mitochondrial encephalopathy and neurodegeneration with high lactate peak in the brain and marked white matter changes), PDPR (typical Joubert syndrome and GDD), PTRH2 (hearing loss, and ataxia also GDD), GEMIN4 (severe

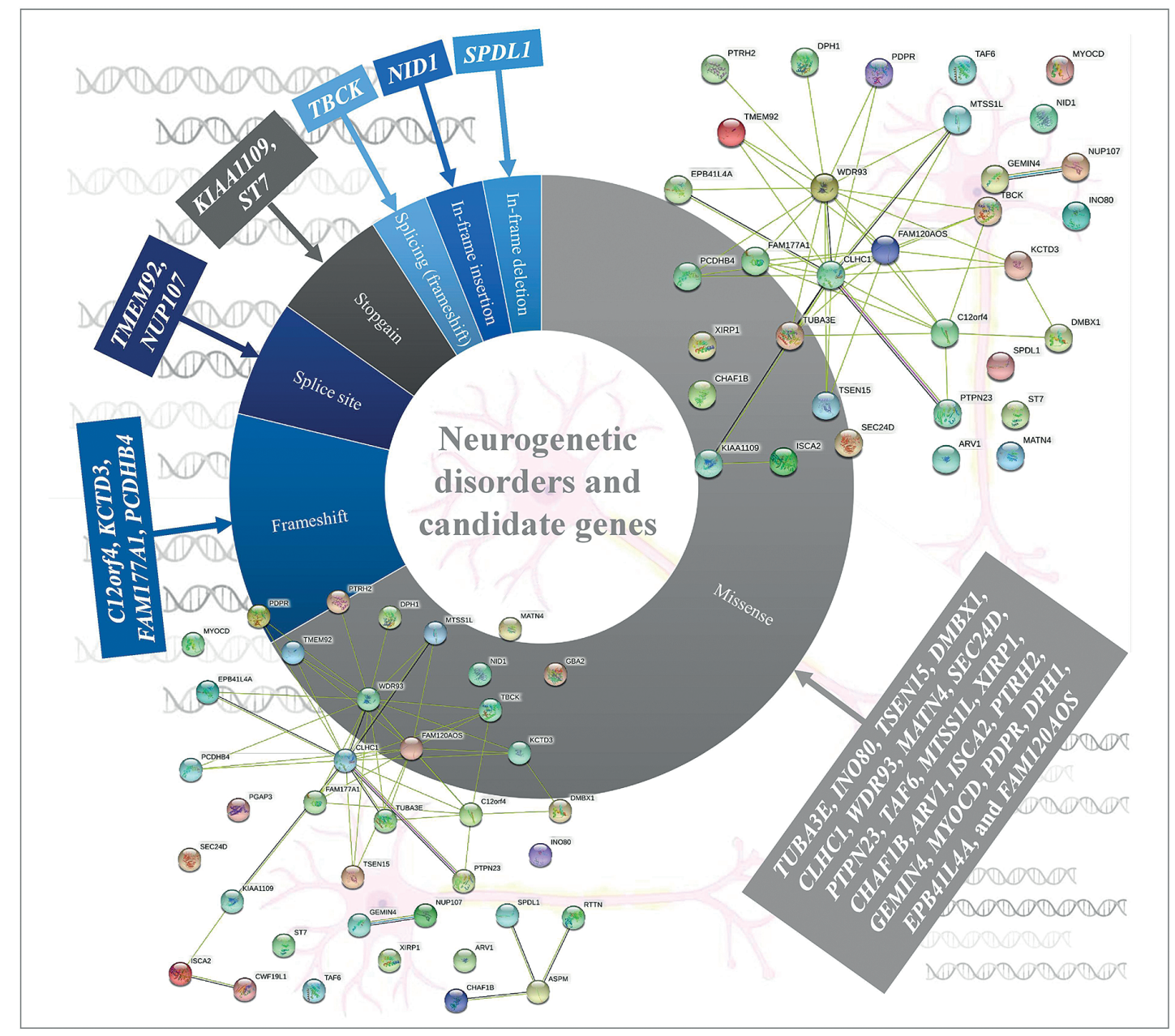

Figure 3. Neurogenetic disorders and candidate genes from WES analysis of pre-screened multiplex consanguineous families of Arab origin. Protein network indicates the protein-protein interaction analysis of genes of neurogenetic disorder candidate genes of Arab population 
osteopenia congenital cataract, tubulopathy, and GDD), DPH1 (Dandy-Walker malformation, developmental delay, cerebellar vermis hypoplasia, and hydrocephalus), NUP107 (early onset focal segmental glomerulosclerosis, light complexion, and global developmental delay), TMEM92 (cerebellar atrophy, hydrocephalus; cognitive, speech, and motor delay), EPBA1L4A (spastic paraplegia, failure to thrive), and FAM120AOS (GERD, chronic lung disease, coarse facial features, skin laxity, scoliosis, hypotonia, undescended testicles and pectus excavatum), were identified among the pre-screened multiplex consanguineous families with neurogenetic disorders. Missense $(n=22)$ variations were common among the disease variations in the patients with neurogenetic disorders (Figure 3) [40]. RTTN and ASPM genes were associated with primary microcephaly apart from those listed above [40-42]. Cerebellar ataxia in a sibling WES study showed a novel variant in the CWF19L1 gene [43] and GBA2 gene in a consanguineous Saudi family [44]. A study on Qatari subjects revealed the association of a novel pathogenic PGAP3 variant with global developmental delay and neuromuscular abnormalities and brain anomalies [45]. Studies on Egyptian subjects revealed the association of pathogenic SCN1OA variation in patients with neuromuscular disease and epileptic encephalopathy [46], SLC39A8 variation in patients with intellectual disability, developmental delay, cerebellar atrophy, hypotonia, strabismus, and variable short stature [47], PQBP1 variation in patients with intellectual disability [48] biotin-thiamine responsive encephalopathy [49] and TTC5 variation in patients with intellectual disability syndromes [50]. The PUS3 gene with a frameshift variant was observed as a candidate gene for intellectual disability in a study with 103 families from Jordan [51]. A family WES study revealed variations in the genes ASPA and ARSA in patients with leukodystrophy in Jordan [52]. Trio exome sequencing of four families from Jordan identified a multi-exon deletion in the VPS13B gene in patients with Cohen syndrome [53]. Consanguineous families from Jordan with neuromuscular disorders identified multiple variants WES in DYSF, MPV17, SLC25A46 and SGCG genes [54]. Lebanese subjects with neurodevelopmental and neuromuscular disorders from 200 WES analyses and other studies revealed various genes with pathogenic variations [55-57]. In order to identify the associated pathways and biological processes associated with the genes identified as the neurogenetic disorders candidate genes of the Arab population, protein-protein interaction analysis was carried out using STRING 10 [58]. The analysis revealed that the genes are linked in terms of text mining, and no significant associated path- ways were identified, which indicates that the impact of cellular processes and pathways needs to be studied to reveal the neurogenetic disorders' candidate genes. Incorporation of proteomics and pathway analysis may reveal the impact of individual genes on neurogenetic disorders in the Arab population and the network of gene-associated pathways on neurogenetic disorders.

\section{Blood and bleeding disorders}

Molecular defects, blood disorders, beta thalassemia, sickle cell disorder, alpha thalassemia and G6PD (glucose-6-phosphate dehydrogenase) deficiency are the most common in the Arab population; they were extensively listed and reviewed earlier [1, 59-63]. The large-scale ( 5000) WES analysis by the SHGP on 1285 cases with 17 blood and bleeding disorders revealed more novel variants $(n=140)$ than previously reported pathogenic variants $(n=98)$ (Table I) among the 821 variants [9, 64-67]. VWF, F8, F5, G6PD, F2, F7, F10, F13B, $F G A$, and $H B A 2$ genes were observed with novel variants. The authors prioritized the list of genes and novel variants in their study, which will definitely be a source of genetic data and will aid in the development of molecular variants' screening and to enhance the efficiency of the preventive programs for the blood and bleeding disorders prevalent in the kingdom [9]. These molecular data will also have a significant impact on developing molecular diagnostic tools for the clinically overlapping disorders with blood and bleeding disorders and to design treatment strategies. VWF, F10, $H B B, F 7$, and $F 5$ genes were observed with notable carrier frequency on the variants associated with Saudi ancestry with blood and bleeding diseases. $V W F, G 6 P D$ and F8 genes are considered as important genes of interest in the prevailing blood and bleeding disorders [9]. The study very precisely ranks the variants based on novelty, pathogenicity and existence in the genomic databases. The study suggested prioritizing autosomal recessive variants in $H B B, F 7, F 13 A 1, F 11$ and VWF genes to screen the carriers for the blood and bleeding disorders prevalent in the Saudi population [9].

\section{Familial transthyretin amyloidosis}

Autosomal dominant disease, familial transthyretin (TTR) amyloidosis (ATTR) was personalized for its genetic predisposition using 13906 Saudi exomes. The authors identified many amino acid substitution variants in the TTR gene and revealed the potential association with amyloidosis (Figure 4) [64]. From a total of 158 TTR mutations identified in the study population, 28 were in the coding and franchising region including 12 nonsynonymous mutations during the analysis of 


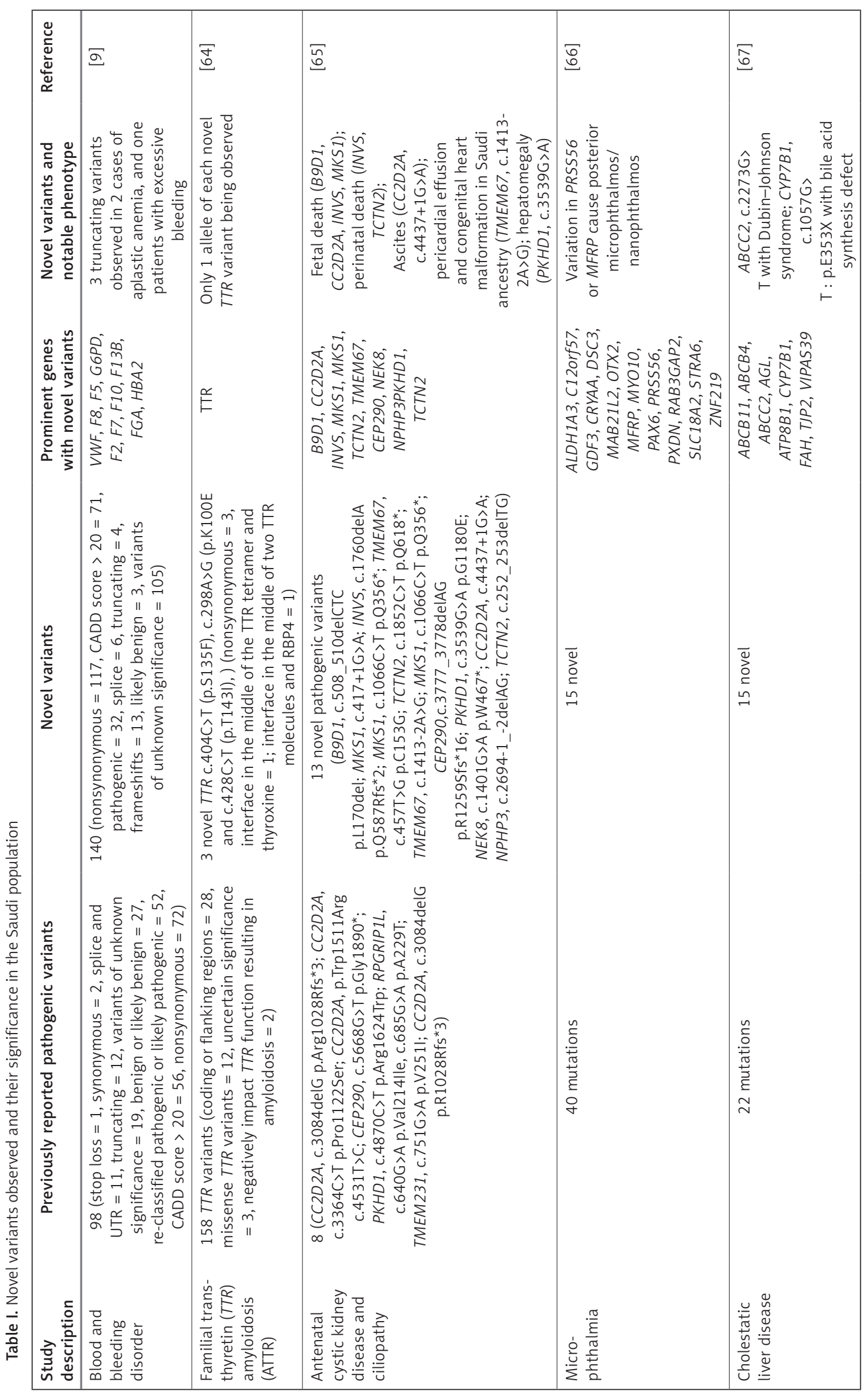




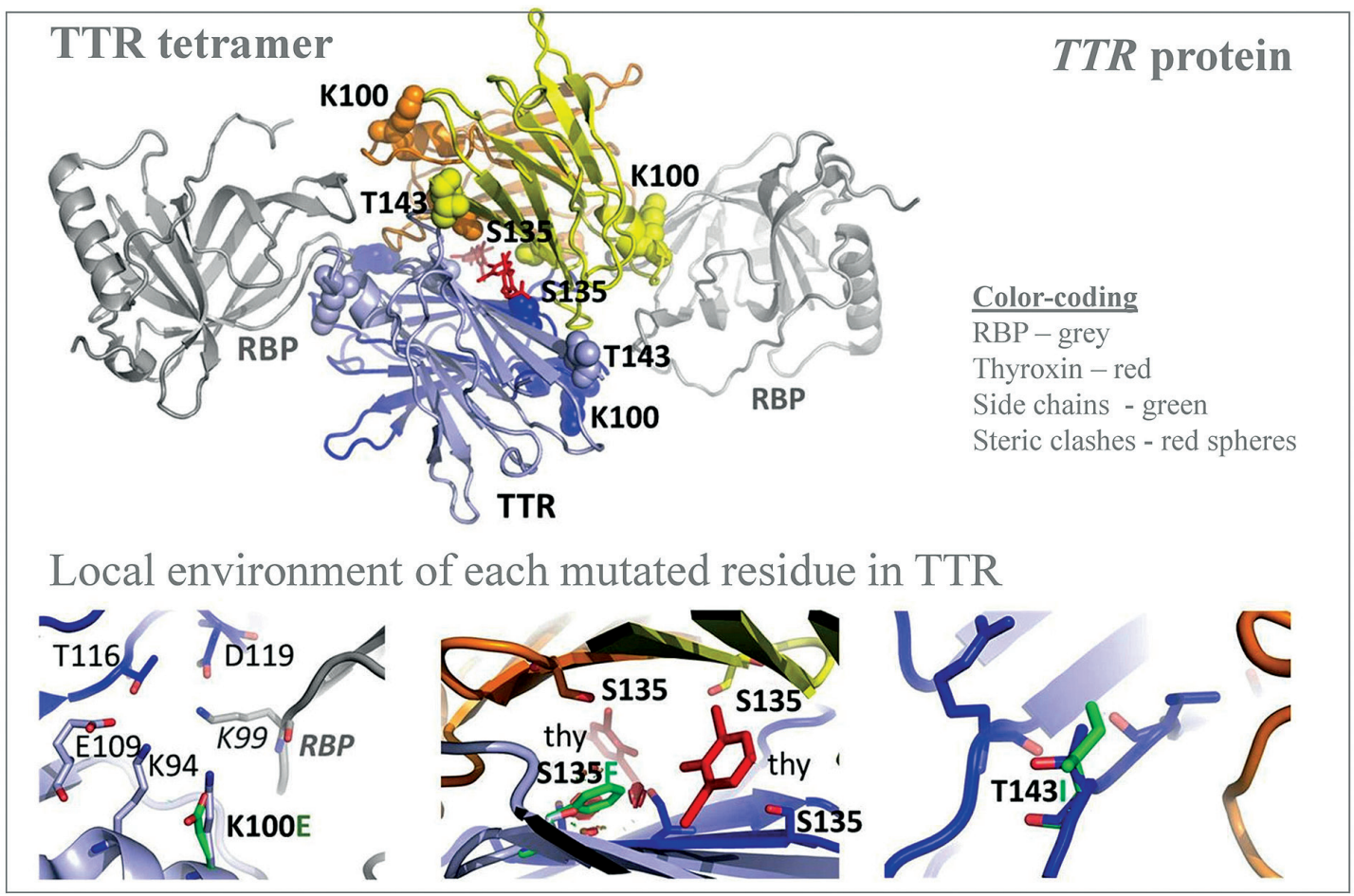

Figure 4. Novel variants observed in TTR gene from Saudi population with familial transthyretin (TTR) amyloidosis (ATTR) or carrier. Modified from Abouelhoda et al. [64]. PDB ID: 2rox used for thyroxin-bound TTR and PDB ID: 2wqa used for RBP-bound TTR

13906 Saudi exomes. Among the 12 missense TTR variants: three (c.239C >T:p.T80I; c.424G>A:p. V142I and c.238A>G:p.T80A) have a known impact on TTR functions; 3 (c.368G>A:p.R123H, c.385G>A:p.A129T and c.370C >T:p.R124C) have unknown significance; three (c.76G>A:p.G26S, c.140A>G:p.N47S and c.328C >A:p.H110N) mutations are benign and likely benign; and the remaining 3 (c.298A>G:p.K100E, c.404C>T:p.S135F, and c.428C>T:p.T143I) are novel variants [64]. Among the 12 missense TTR variants, 2 mutations [less frequent c.238A>G:p.T80A (0.00004), most prevalent c.424G>A:p.V142I (0.001)] are associated with amyloidosis, with a well-known pathogenic impact on the function of the TTR protein [64]. This study is the first large-scale study on analyzing the TTR mutations from the Saudi population. Even though three novel variants were reported in this study on Saudis with systemic amyloidosis, the known and previously reported mutation TTR:c.424G>A(p.V142I) is the variant observed most frequently in the Arabian ancestry [64]. This particular mutation is frequently identified in African descendants and the African American population. A common variant observed in Ireland and the United Kingdom, TTR:c.238A>G(p.T80A), is rare in the Arabian population [64]. Many variants of the TTR gene reported from Western Europe, Italian and Denmark populations were not observed in the Saudi ancestry; furthermore, the most common mutation observed in the TTR gene from Chinese and Mexican populations was also not observed in the Saudi ancestry including the 5 regions of Saudi Arabia. This study has a major limitation accessing the clinical data related to the novel TTR variants and the variance observed in the TTR gene, this very clearly indicates that more clinical and genetic studies are needed in order to reveal the clinical manifestations of the observed mutations in the Saudi ancestry.

\section{Fetal death and perinatal death}

A comprehensive genomic analysis on 34 families with fetal death, perinatal death and renal phenotype (enlarged, echogenic with cysts, cystic) revealed genes and novel variants associated with fetal death (B9D1, CC2D2A, and MKS1) and perinatal death (INVS and TCTN2) [65]. The study revealed 13 novel pathogenic variants [(Frame shift: INVS:C.1760delA; and CEP290:C.3777_3778delAG); deletions: B9D1:C.508_510delCTC; NPHP3:C.26941_-2delAG; and TCTN2:C.252_253delTG; CC2D2A: c.4437+1G>A; MKS1:c.417+1G>A; MKS1:c.1066C >T; TCTN2:C.1852C>T; NEK8:c.1401G>A; TMEM67: c.457T>G; TMEM67:C.1413-2A>G; MKS1:C. 1066C >T; PKHD1:C.3539G >A); this clearly indicates the genetic heterogeneity. In additions to renal defects, ascites (CC2D2A), pericardial effusion and congenital heart malformation (TMEM67), and hepatomegaly (PKHD1) were also reported [65]. The most prevalent cause of an antenatal cil- 
iopathy is due to $C C 2 D 2 A$ gene variation among the families studied. Variations in FRAS1 and FREM 2 genes were identified in six consanguineous Saudi Arabian families with antenatal/perinatal death [68].

\section{Intellectual disability}

Intellectual disability is the most prevalent genetic disorder in terms of carrier frequency in the Saudi population (Figure 2) [7]. Temtamy syndrome is a type of intellectual impairment with epilepsy, ocular involvement and corpus callosum dysgenesis. A detailed study on temtamy syndrome exposed a high carrier frequency of start loss mutation [c.1A>G; p.M1?] in the chromosome
12 open reading frame 57 (C12orf57) gene in the Saudi population; it was the first observation of the syndrome for C12orf57. The study showed variable phenotypic in the cases with intellectual disability. The study conclusively reported the C12orf57 gene variants in the pathology of intellectual disability/developmental delay in the Arab population. Interestingly, the observations on the absence of typical syndromic features in Saudi ancestry are associated with intellectual disability, which is common and recessive. The start loss mutation [c.1A>G; p.M1?] in the C12orf57 gene is the most frequently prevalent $(80.3 \%$ of all cases studied) disease marker in the Saudi ancestry (Figure 5) [69]. Another 6 variants in addition to start loss variation in the C12orf57 gene were re-
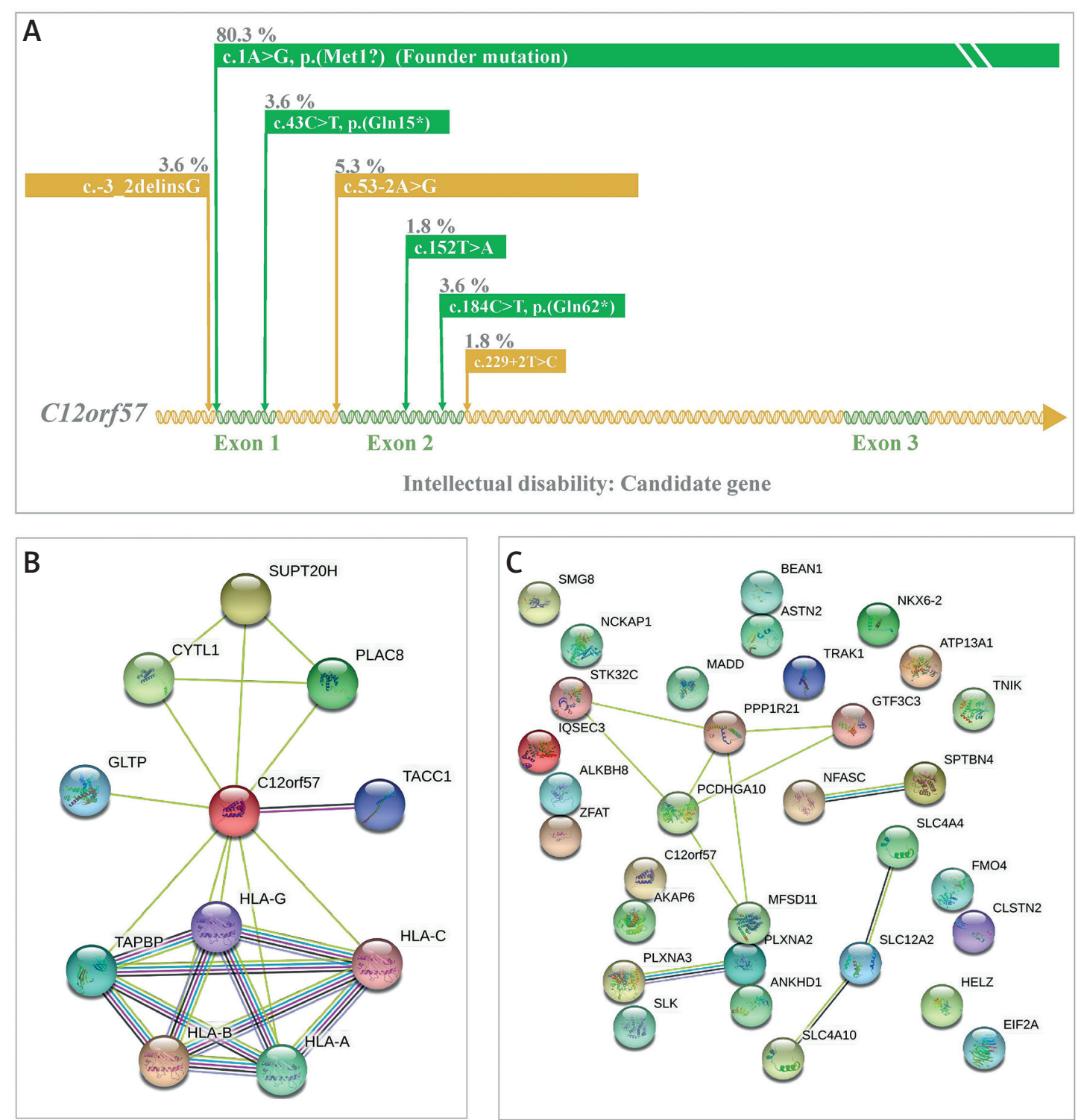

Figure 5. A - Disease markers of intellectual disability in C12orf57 gene. Variants and their percentage contribution to the presence of intellectual disability in Saudi population. B - Protein-protein interaction analysis of C12orf57 gene with literature using STRING [58]. C - Protein-protein interaction analysis of genes of intellectual disability candidate genes of Arab population 
ported (Figure 5) [69]. The seven variations in the C12orf57 gene are the founder mutation $c .1 A>G$, p.(Met1?), c.53-2A>G, c.184C >T, p.(Gln62*), p. $\left(\mathrm{G} \ln 15^{\star}\right), \quad$ c.229+2T>C, c.-3_2delinsG, c.43C $>T$, and c.152T>A, p.(Leu51GIn) accumulated in exons 1 and 2 (Figure 5) [69]. The C12orf57 gene was also associated with microphthalmia in the Saudi population (Table I) [66]. Large-scale exome sequencing and other studies reported the association between variations in AKAP6, ALKBH8, CLSTN2, EIF2A, IQSEC3, PLXNA2, PLXNA3, SMG8, BEAN1, HELZ, SLC4A4, SLC4A10 and TNIK and intellectual disability [70-75]. Intellectual disability patients $(n=105)$ from 68 families were identified with intellectual disability candidate genes such as ASTN2, ANKHD1, FMO4, ATP13A1, GTF3C3, MADD, NCKAP1, STK32C, NFASC, MFSD 11, NKX62, PCDHGA10, SLC12A2, PPP1R21, SLK, SPTBN4, TRAK1, and ZFAT [76]. Expression analysis confirmed the intellectual disability candidate gene, NCKAP1 [76]. A study on Qatari subjects revealed the association of the novel pathogenic PGAP3 variant with hyperphosphatasia with mental retardation, global developmental delay and neuromuscular abnormalities and brain anomalies [45]. Protein-protein interaction analysis of the C12orf57 gene with the literature using STRING revealed the high interaction with $H L A$ genes and associated pathways (Figure 5 B) [58]. Studies from Egyptians and Jordanians revealed the association of pathogenic SLC39A8, PQBP1, TTC5 and PUS3 variation in patients with intellectual disability [47, 48, 50, 51]. WES analysis from Lebanese subjects with intellectual disability identified the association of pathogenic variations in COQ8A and MED25 [77]. Further, the protein-protein interaction analysis (STRING [58]) of genes of intellectual disability candidate genes of the Arab population from various studies revealed (Figure $5 \mathrm{C}$ ) the most significant ( $p$ value $<0.05$ ) biological processes, neuron differentiation (C120rf57, SPTBN4, TRAK1, NFASC, NCKAP1, PLXNA2, NKX62, PLXNA3, SLC4A10, and TNIK), neuron development (C12orf57, SPTBN4, TRAK1, NFASC, NCKAP1, PLXNA2, PLXNA3, SLC4A10, and TNIK), neuron projection morphogenesis (C12orf57, SPTBN4, TRAK1, NFASC, NCKAP1, PLXNA2, PLXNA3, and $T N I K)$, central nervous system neuron differentiation (C120rf57, SPTBN4, NKX6-2, PLXNA3, and SLC4A10), central nervous system neuron development (C12orf57, SPTBN4, PLXNA3, and SLC4A10) and generation of neurons (C120rf57, SPTBN4, TRAK1, NFASC, NCKAP1, ASTN2, PLXNA2, NKX6-2, PLXNA3, SLC4A10, and TNIK).

\section{Microphthalmia}

Genetic investigation using multi-gene panel and WES on 93 families with developmental eye defect (microphthalmia) revealed 55 point variations in 24 disease genes, including 15 novel variations [66]. In addition, the study discovered interesting candidate variations in two genes, MYO10 and ZNF219, that have not been related to human disorders, which were notable novel possibilities for microphthalmia in the study, most of whom were Saudis, and there were 14 Egyptian and Lebanese subjects [66]. SLC18A2, PAX6, DSC3 and CNKSR1 genes are very rarely linked in the families with microphthalmia.

\section{Metabolic traits}

Despite concerted efforts at a national level to promote awareness about the dangers of a sedentary lifestyle and consuming fast food, the people in the Arab regions continue to be at risk for metabolic diseases. There are no well-known genetic risk factors for metabolic diseases in the Arab population like the European population, and the existing genetic risk loci for metabolic traits in the Arab population have not been shown adequately. A recent GWAS study on an Arab (Kuwaiti) population to identify genetic risk factors for quantitative characteristics including anthropometry, insulin resistance, lipid profile, and levels of blood pressure failed to discover associated recessive variations or were unable to replicate the identified loci [78]. This is mainly due to the complicated gene-environment interactions in Arab ancestries. However, another study on the same population identified the TNKS haplotype associated with hypertension [36].

\section{Other genetic diseases}

Variants in the Mendeliome in Saudi ancestry - APC-related Cenani-Lenz syndrome, Steel syndrome, syndromic cataract, oral-facial-digital syndrome, CHARGE-like presentation, epileptic encephalopathy, Ehlers-Danlos-like syndrome, and congenital hydrocephalus - were reported either with compatible phenotypes (homozygous variant in 30 genes) or phenotypes different from the original reports (homozygous mutations in 18 candidate genes) [79]. Studies on systemic juvenile idiopathic arthritis (LACC1 gene) [80, 81]; recurrent pregnancy loss (ASIC5 gene) [82]; tricho-hepato-enteric syndrome (SKIV2L and TTC37 genes) [83]; STING-associated vasculopathy of infantile-onset (STING1 gene) [84]; multiple congenital anomaly syndrome (SMG9 gene) [85]; diabetic retinopathy (NME3, LOC728699, and FASTK genes) [86]; congenital neutropenia with inflammatory bowel disease (G6PC3 gene) [87]; skeletal dysplasia (XYLT1) [88, 89]; WolfHirschhorn syndrome (WHSC1 gene) [90]; lymphatic dysplasia with nonimmune hydrops fetalis (PIEZO1) [89]; Cohen syndrome (VPS13B gene) 
[91]; severe combined immunodeficiency disease (AK2, JAK3, and MTHFD1 genes) [92]; celiac disease (CPED1 gene) [93]; hereditary spherocytosis type 3 (SPTA1 gene) [89]; developmental delay, cerebellar hypoplasia, and myoclonic seizures (KCNMA1 gene) [74]; Cenani-Lenz syndrome (APC gene) [74]; Sjogren-Larsson syndrome (ELOVL4 gene) [74]; autism spectrum disorder (multigene) [94]; congenital heart disease (PRKD1 gene) [95]; ciliopathies [96]; Parkinsonism (PLA2G6 gene) [97]; retinal dystrophies (CLRN1, ABCA4, CERKL, AGBL5, CDH16, and DNAJC17 genes) [98-100]; pediatric asthma [101]; cardiovascular genetic diseases (LDLR gene) [102]; enteroendocrine dysfunction (PCSK1) [103]; tricho-hepato-enteric syndrome (TTC37 and SKIV2L) [104]; Wolcott-Rallison syndrome (EIF2AK3) [105], Fanconi-Bickel syndrome (SLC2A2) [105] and Alström syndrome (exon 19 skipping in ALMS1 gene) $[106,107]$ using whole exome or whole genome analysis revealed disease markers in the Saudi population. Families with autosomal recessive retinal dystrophies from various ethnicities including Saudis were analyzed for candidate genes using WES; 45 unique deleterious variants including 18 novel variants were observed [108]. UGCG (UDP-glucose ceramide glucosyltransferase) gene related ichthyosis was reported from a single Saudi family, caused by NM_003358:exon2:c.142dupA variations in the UGCG gene [109]. Epileptic encephalopathy in a consanguineous family was exome analyzed and a pathogenic variation in the FRRS1L [c.961C>T: p. $\left(\mathrm{G} \ln 321^{*}\right)$ ] gene was identified [110]. The NOTCH4 gene with a truncating and a splice variant was observed in 2 Saudi patients with
Parkinson's disease [111]. Furthermore, the study reported 18 genes (121 mutations) in Parkinson's disease in 60 Saudis; most of the variants are missense $(n=90)$ and nonsense $(n=11)$ [111]. Gene specific pathogenic variant analysis of an Arab population of Qataris ( $n=6045$ whole-genome sequencing) revealed the most pathogenic and likely pathogenic variants in the SCN5A ( $n=37$ variants) gene followed by ATP7B ( $n=26$ variants), $L D L R$ ( $n=22$ variants) and $R Y R 1$ ( $n=20$ variants) (Figure 6) [112]. The study revealed genes associated with Li-Fraumeni syndrome (TP53 gene); Peutz-Jeghers syndrome (STK11 gene); Lynch syndrome (MSH6, MLH1, PMS2, and MSH2 genes); familial adenomatous polyposis (APC gene); juvenile polyposis (SMAD4 and BMPR1A genes); Von Hippel-Lindau syndrome (VHL gene); multiple endocrine neoplasia type 1 (MEN1 gene); familial medullary thyroid cancer (RET gene); multiple endocrine neoplasia type 2 (RET gene); PTEN hamartoma tumor syndrome (PTEN gene); WT1-related Wilms tumor (WT1 gene); retinoblastoma (RB1 gene); hereditary paraganglioma pheochromocytoma syndrome (SDHAF2, SDHD, SDHB and SDHC genes); neurofibromatosis type 2 (NF2 gene); Loeys-Dietz syndromes, Marfan syndrome, and familial thoracic aortic aneurysms and dissections (TGFBR2, FBN1, ACTA2, TGFBR1, MYH11 and SMAD3 genes); tuberous sclerosis complex (TSC1 and TSC2 genes); Ehlers-Danlos syndrome (COL3A1 gene); Wilson disease (ATP7B gene); dilated cardiomyopathy, hypertrophic cardiomyopathy (MYH7, MYBPC3, TPM 1, MYL3, TNNT2, TNNI3, LMNA, ACTC1, MYL2, PRKAG2 and GLA genes), arrhythmogenic right ventricular cardiomyopathy

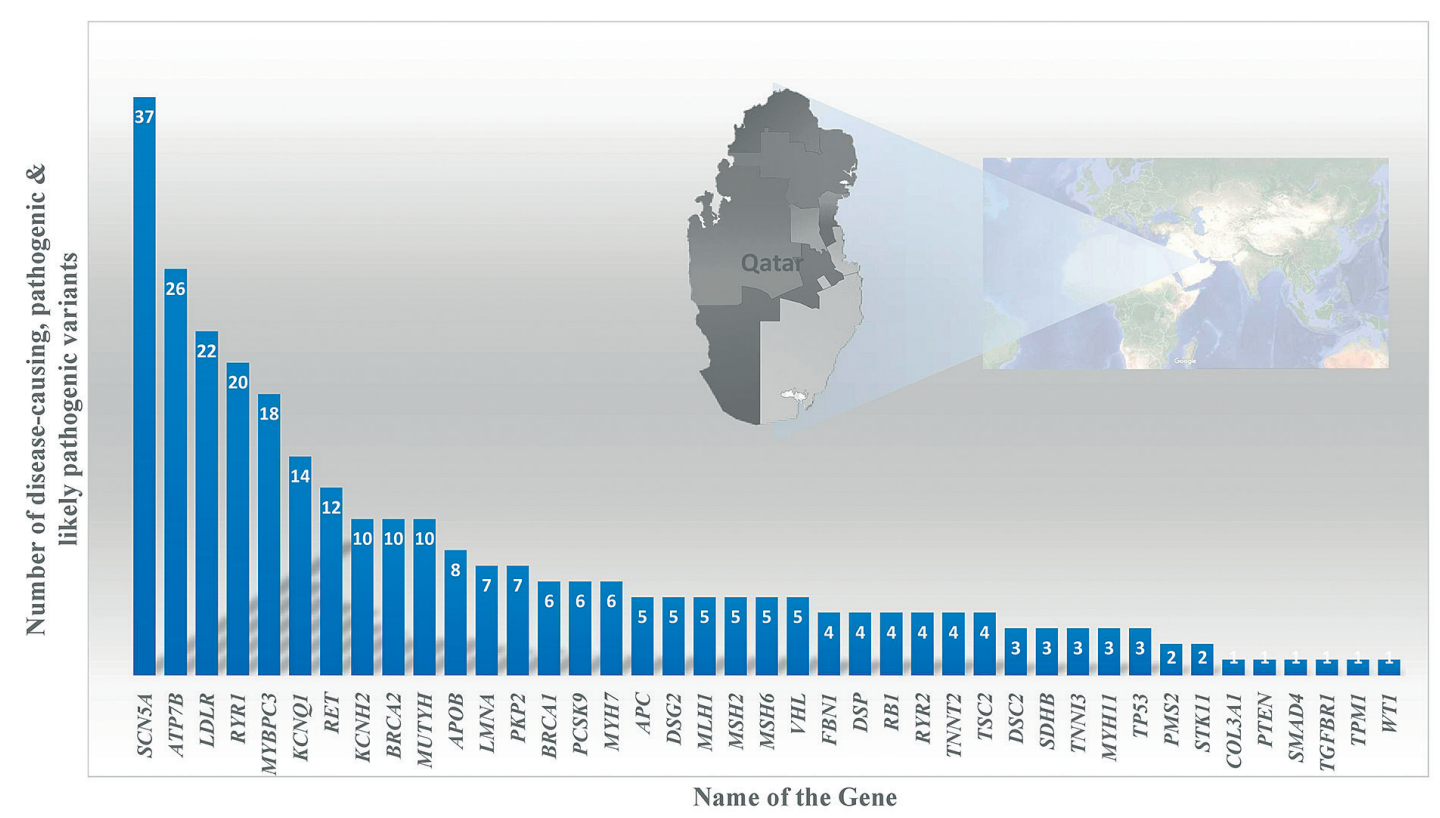

Figure 6. Number of disease-causing, pathogenic and likely pathogenic variants per gene through 6045 WGS of Qataris from QGP 
(DSC2, TMEM43, PKP2, DSP, and DSG2 genes); catecholaminergic polymorphic ventricular tachycardia (RYR2 gene); long QT and Brugada syndrome (SCN5A, KCNH2, and KCNQ1 genes); malignant hyperthermia susceptibility (RYR1 and CACNA1S genes); familial hypercholesterolemia (PCSK9, $A P O B$, and $L D L R$ genes); and ornithine transcarbamylase deficiency (OTC gene) diseases in an Arab population ( $n=6045$ Qataris, whole-genome sequencing) [112]. Low bone mineral density associated variants were found in non-coding RNA MALAT1 (antisense TALAM1), FASLG, SAG, LSAMP and FAM189A2 from a Qatari based Arab population with 3000 WGS [113] and the ILIRL1 gene variant with familial Mediterranean fever [114]

Studies (WES) in Egyptian individuals revealed associated genes of primary hyperoxaluria type I (AGXT gene), infantile hypercalcemia/hypophosphatemia/nephrolithiasis (SLC34A1 gene) [115], severe combined immunodeficiency (JAK3 gene) [116], propionic acidemia (PCCA gene) [117], sulfite oxidase deficiency (SUOX gene), molybdenum cofactor deficiency (MOCS2 gene) [118], primary hereditary microcephaly (ASPM gene) [119], familial Mediterranean fever (MEFV gene) [120], thiamine-responsive megaloblastic anemia (SLC19A2 gene) [121], cerebellar atrophy and developmental delay (PLA2G6, KIF1A and MOCS2A genes) [122], micro-/anophthalmia (VSX2, SOX2, and FOXE3 genes) [123], RAG-deficiency (RAG1 and RAG2 genes) [124], auriculocondylar syndrome (PLCB4, GNA13, and EDN1 genes) [125], ectodermal dysplasia (EDA, EDAR, and EDARADD genes) [126], 3-phosphoglycerate dehydrogenase deficiency (PHGDH gene) [127], Carpenter syndrome (RAB23 gene) [128], disorders/differences of sex development (NR5A1, CYP19A1, AMH, AMHR2, WT1, HHAT, and FANCA and in the X-linked genes KDM6A and ARX genes) [129] and autosomal recessive polycystic kidney disease (PKHD1 gene) [130]. WES studies in Iraqi people revealed associated genes of epileptic encephalopathy (SLC13A5 gene) [131], juvenile neuronal ceroid lipofuscinoses (CLN3 gene) [132], inherited thrombocytopenia (FYB gene) [133], microcephaly (TMX2 gene) [134], non-syndromic retinal dystrophy (POC1B gene) [135], progressive pseudorheumatoid dysplasia (WISP3 gene) [136], dedicator of cytokinesis 8 deficiency (DOCK8 gene) [137], and developmental delay (MED27 gene) [138]. A Jordanian patient with hypotrichosis-lymphedema-telangiectasia syndrome was analyzed using WES for causative genetic factors; the study revealed the SOX18 mutation associated with the syndrome [139]. WES analysis of four consanguineous Jordanian families detected the causative genetic variant responsible for an unknown gastrointestinal related diseases [140]. Across the five con- sanguineous families, four variations in the $R P 1$ and $R L B P 1$ genes were identified as disease-causing variants in patients with retinitis pigmentosa [141]. Two novel pathogenic variants in the DYSF gene were identified in the patients with muscular dystrophies from consanguineous Jordanian families [142]. Eight Jordanian consanguineous families with multiple keratoconic individuals were analyzed using WES, which revealed two variants in the genes MYOF and STX2, and one variant in the genes COL6A5, ZNF676 and ZNF765 [143]. WES analysis of Lebanese subjects with various genetic disorders (renal dysfunction, PKHD1, GRHPR and NPHS2 genes) revealed associated genes with the overall success rate of $56 \%$ [55]. Other studies on Lebanese with cytochrome c oxidase deficiency (PET100 gene) [144], discoid lupus erythematosus (TRAF3IP2 gene) [145], Bardet-Biedl and Usher syndromes (BBS9, ARL6, BBS12 and BBS5 genes) [146] and Basel-Vanagaite-Smirin-Yosef syndrome (MED25 gene) [147] revealed the causative genes. Genetic polymorphisms in Arab individuals with obesity were discussed previously [148-150].

Genetic analysis on Saudi patients $(n=98)$ with cholestatic liver disease revealed 37 variations including 15 novel mutations in $A B C B 11$, ABCB4, ABCC2, AGL, ATP8B1, CYP7B1, FAH, TJP2, and VIPAS39 [67]. The $A B C B 11$ gene was reported with the most common candidate disease marker gene among $25 \%$ of cases studied [67]. In Saudi patients ( $n=261$ ) with primary immunodeficiency an NGS sequencing platform through a targeted gene panel (162 PID genes) revealed 89 mutations (45 mutations and 44 novels) [151]. Sickle cell disease is the $5^{\text {th }}$ most prevalent genetic disorder in terms of carrier frequency in the Saudi population [7]. High fetal hemoglobin ( $\mathrm{HbF}$ ) in sickle cell patients is common among Saudis; whole genome studies may reveal candidate HbF-modulating genes and 'missing heritability' in the Arab ancestries. WES based Trio $(n=16)$ analysis of attention deficit hyperactivity disorder (ADHD) reported 32 rare variants in 31 candidate genes; exclusively 5 genes (PSRC1, PTP4A3, NEK4, NLE1, and TMEM183A) were first observed among the Saudi ancestry [152]. Genomic studies on congenital microcephaly proposed BPTF, CCNH, MAP1B, and PPFIBP1 genes as candidate genes and confirmed ANKLE2, THG1L, YARS, and FRMD4A genes as congenital microcephaly candidate genes [153]. Targeted sequencing on Saudi patients (14 families) with Glanzmann thrombasthenia discovered 17 variants in ITGA2B and ITGB3 genes including 6 novel mutations [154]. The largest Arab study on 80 patients from 72 families (mostly consanguineous) with peroxisomal disorders (molecularly characterized) identified disease-causing variants ( $n=43 ; 50 \%$ novel) and estimated the disease 
burden ( 1 : 30,000) [155]. Exome sequencing and immunophenotyping of CARMIL2-deficient T cells confirmed the candidature of a novel $13 \mathrm{bp}$ frameshift deletion (c.2536_2548del) and substitution p.R50T in the CARMIL2 gene for combined immunodeficiencies [156].

\section{Mitogenome}

Sequencing and analysis of the entire mitochondrial DNA (mtDNA) genomes of Emirate females $(n=232)$ and comparison with African ancestries were carried out to characterize the genetic landscape of the Arab population from United Arab Emirates [157]. The mitochondrial genome of the Arab (Emirati) population from the United Arab Emirates revealed the prevalence of haplogroups, heteroplasmy, genetic variation, and demography. The study revealed 968 variations in the mtDNA genome in 15 haplogroups. Another study on the mitogenome of the Kuwaiti population (288 whole-exome) identified 1,241 mtDNA SNPs [158]. In a Qatari $(n=864)$ population mitogenome analysis of $1831 \mathrm{mtDNA}$ variants including 56 indels and 1775 SNPs was performed [159]. A report from the Emirati population showed that the Arab population received sufficient gene flow from African ancestries. Furthermore, the study showed that the Arab population received sufficient gene flow from Africa ancestries and a demographic bottleneck was observed that occurred around the time of Western European contact [157]. Since the earliest modern humans emerged from Africa, multiple maternal lineage migratory events favoring African-Asian corridors have occurred, according to the research based on UAE mitogenomes [157]. Ancestral sharing with Afri$\mathrm{ca}$, the Near East and East Asia was also revealed from the study [157]. Complete mitochondrial haplogroup analysis in Arab populations from Qatar and Kuwait based investigations revealed the relationship of mtDNA variations with obesity $[158,159]$. The missense variant identified in the MT-ND2 gene, MT:5460G > A, in the Kuwaiti population is the most significant mtDNA variation associated with obesity [158].

\section{Summary and future directions}

Even though the KGP, SHGP, QGP, BGP and EGP are revisiting the genetics and genomics of Arab populations' ancestries, lack of complete coordination between the initiatives is a major limitation on revealing the real disease markers of the Arab population [6]. Recent genomic studies identified more than 3000 new nucleotide variations linked to more than 1200 uncommon genetic diseases and numerous pathogenic variants in HGMD and the ClinVar Database have been reclassified as benign. However, more root level studies are needed on validating these changes from pathogenic to benign using Sanger sequencing and expression levels in the Arab population. More attention is needed on levels of intellectual impairment as they are the highest among Saudi Arabians from consanguineous families. Large-scale genomic research has opened up a fresh perspective on Mendelian genes and disorders. Arab research institutions must make a concerted effort to develop better strategies for doing more large-scale genotype-phenotype association studies in hereditary disorders prevalent in the region. Whole genome sequencing in large-scale control subjects including patients with inherited diseases can discover the molecular basis in the unsolved cases in the Arabian studies. Transcriptome studies in the Saudi population shall reveal the functional and molecular impact on the disease development by the candidate genes and pathogenic variations. Novel variants observed in inherited diseases will be the best resource for the developing disease marker panel for the Arab ancestry. Complicated geneenvironment interactions in Arab ancestries with various diseases will open real networking factors on complex diseases prevalent in the Arab population. National coordination between regional research centers in the country and in the Arab region can reveal in-depth gene networks in diseases and associated pathways.

\section{Acknowledgments}

The author thanks the Dean, Institute for Research and Medical Consultations (IRMC), Imam Abdulrahman Bin Faisal University, Dammam, Saudi Arabia, for her continuous support and encouragement. The author thanks Dr Sayed Abdul Azeez for critical comments. The author thanks the Deanship of Scientific Research, Imam Abdulrahman Bin Faisal University (Grant No: $2017-$ 100-IRMC). The funders had no role in the study design, decision to publish, or preparation of the manuscript.

\section{Conflict of interest}

The author declares no conflict of interest.

\section{References}

1. Tadmouri GO, Sastry KS, Chouchane L. Arab gene geography: from population diversities to personalized medical genomics. Glob Cardiol Sci Pract 2014; 2014: 394-408.

2. Saudi Genome Project Team. The Saudi Human Genome Program: An oasis in the desert of Arab medicine is providing clues to genetic disease. IEEE Pulse 2015; 6: 22-6.

3. Abdul Rahim HF, Ismail SI, Hassan A, et al. Willingness to participate in genome testing: a survey of public attitudes from Qatar. J Hum Genet 2020; 65: 1067-73. 
4. Thareja G, John SE, Hebbar P, Behbehani K, Thanaraj TA, Alsmadi O. Sequence and Analysis of a whole genome from Kuwaiti population subgroup of Persian ancestry. BMC Genomics 2015; 16: 92.

5. Al-Ali M, Osman W, Tay GK, AlSafar HS. A 1000 Arab genome project to study the Emirati population. J Hum Genet 2018; 63: 533-6.

6. Ghaly M, Sadoun E, Alkuraya F, Fakhro K, Ismail S, Ben-Omran T. Genomics in the Gulf region and Islamic ethics. World Innovation Summit for Health 2016.

7. Abouelhoda M, Sobahy T, El-Kalioby M, et al. Clinical genomics can facilitate countrywide estimation of autosomal recessive disease burden. Genet Med 2016; 18: 1244-9.

8. Abouelhoda M, Faquih T, El-Kalioby M, Alkuraya FS. Revisiting the morbid genome of Mendelian disorders. Genome Biol 2016; 17: 235.

9. Baz B, Abouelhoda M, Owaidah T, Dasouki M, Monies D, Al Tassan N. Molecular classification of blood and bleeding disorder genes. NPJ Genom Med 2021; 6: 62 .

10. Alkuraya FS. Genetics and genomic medicine in Saud Arabia. Mol Genet Genomic Med 2014; 2: 369-78.

11. Al-Gazali L, Hamamy H, Al-Arrayad S. Genetic disorders in the Arab world. BMJ 2006; 333: 831-4.

12. Zayed $\mathrm{H}$. The Arab genome: health and wealth. Gene 2016; 592: 239-43.

13. Fakhro KA, Robay A, Rodrigues-Flores JL, et al. Point of care exome sequencing reveals allelic and phenotypic heterogeneity underlying Mendelian disease in Qatar. Hum Mol Genet 2019; 28: 3970-81.

14. Peric J, Samaradzic N, Trifunovic V, et al. Genomic profiling of thymoma using a targeted high-throughput approach. Arch Med Sci 2020; doi:10.5114/ aoms.2020.96537

15. Skrzypczak-Zielinska M, Gabryel M, Marszalek D, Dobrowolska A, Slomski R. NGS study of glucocorticoids response genes in inflammatory bowel disease patients. Arch Med Sci 2021; 17: 417-33.

16. Fakhro KA, Staudt MR, Ramstetter MD, et al. The Oatar genome: a population-specific tool for precision medicine in the Middle East. Hum Genome Var 2016; 3: 16016.

17. Alabdulkareem IB, Robertson AJ, Al Garawi S, Aljumah M, Al-Turki S, Al Balwi MA. Distinctive Features of a Saudi Genome. Genomics 2015.

18. John SE, Thareja G, Hebbar P, Behbehani K, Thanaraj TA, Alsmadi O. Kuwaiti population subgroup of nomadic bedouin ancestry - whole genome sequence and analysis. Genom Data 2015; 3: 116-27.

19. Almarri MA, Haber M, Lootah RA, et al. The Genomic History of the Middle East. Genomics 2020.

20. Mbarek H, Gandhi GD, Selvaraj S, et al. Qatar genome: insights on genomics from the Middle East. Genetic and Genomic Medicine 2021.

21. Al-Dewik N, Ben-Omran T, Zayed H, et al. Clinical exome sequencing unravels new disease-causing mutations in the myeloproliferative neoplasms: a pilot study in patients from the state of Qatar. Gene 2019; 689: 34-42.

22. Daw Elbait G, Henschel A, Tay GK, Al Safar HS. A population-specific major allele reference genome from The United Arab Emirates population. Front Genet 2021; 12: 660428.

23. Saudi Mendeliome Group. Comprehensive gene panels provide advantages over clinical exome sequencing for Mendelian diseases. Genome Biol 2015; 16: 134

24. Thareja G, Al-Sarraj Y, Belkadi A, Almotawa M; Qatar Genome Program Research (QGPR) Consortium; Suhre K,
Albagha OME. Whole genome sequencing in the Middle Eastern Qatari population identifies genetic associations with 45 clinically relevant traits. Nat Commun 2021; 12: 1250

25. Al Thani A, Fthenou E, Paparrodopoulos S, et al. Qatar biobank cohort study: study design and first results. Am J Epidemiol 2019; 188: 1420-33.

26. Gurdasani D, Carstensen T, Fatumo S, et al. Uganda genome resource enables insights into population history and genomic discovery in Africa. Cell 2019; 179: 984-1002.e36.

27. Pilia G, Chen WM, Scuteri A, et al. Heritability of cardiovascular and personality traits in 6,148 Sardinians. PLoS Genet 2006; 2: e132.

28. Zaitlen N, Kraft P, Patterson N, et al. Using extended genealogy to estimate components of heritability for 23 quantitative and dichotomous traits. PLoS Genet 2013; 9: e1003520.

29. Kanai M, Akiyama M, Takahashi A, et al. Genetic analysis of quantitative traits in the Japanese population links cell types to complex human diseases. Nat Genet 2018; 50: 390-400.

30. Yousri NA, Fakhro KA, Robay A, et al. Whole-exome sequencing identifies common and rare variant metabolic QTLs in a Middle Eastern population. Nat Commun 2018; 9: 333.

31. AlSafar HS, Al-Ali M, Elbait GD, et al. Introducing the first whole genomes of nationals from the United Arab Emirates. Sci Rep 2019; 9: 14725.

32. Daw Elbait G, Henschel A, Tay GK, Al Safar HS. Whole genome sequencing of four representatives from the admixed population of the United Arab Emirates. Front Genet 2020; 11: 681.

33. Eaaswarkhanth $M$, Pathak AK, Ongaro L, et al. Unraveling a fine-scale high genetic heterogeneity and recent continental connections of an Arabian Peninsula population. Eur J Hum Genet 2022; 30: 307-19.

34. Scott EM, Halees A, Itan Y, et al. Characterization of Greater Middle Eastern genetic variation for enhanced disease gene discovery. Nat Genet 2016; 48: 1071-6.

35. Hajjej A, Almawi WY, Arnaiz-Villena A, Hattab L, Hmida $\mathrm{S}$. The genetic heterogeneity of Arab populations as inferred from HLA genes. PLoS One 2018; 13: e0192269.

36. Eaaswarkhanth M, Dos Santos ALC, Gokcumen O, Al-Mulla F, Thanaraj TA. Genome-wide selection scan in an Arabian Peninsula population identifies a TNKS haplotype linked to metabolic traits and hypertension. Genome Biol Evol 2020; 12: 77-87.

37. Al-Zahery N, Pala M, Battaglia V, et al. In search of the genetic footprints of sumerians: a survey of Y-chromosome and MtDNA variation in the Marsh Arabs of Iraq. BMC Evol Biol 2011; 11: 288.

38. Fadhlaoui-Zid K, Martinez-Cruz B, Khodjet-el-khil H, Mendizabal I, Benammar-Elgaaied A, Comas D. Genetic structure of Tunisian ethnic groups revealed by paternal lineages. Am J Phys Anthropol 2011; 146: 271-80.

39. Nair P, Sabbagh S, Mansour H, et al. Contribution of next generation sequencing in pediatric practice in Lebanon. A study on 213 cases. Mol Genet Genomic Med 2018; 6: 1041-52.

40. Alazami AM, Patel N, Shamseldin HE, et al. Accelerating novel candidate gene discovery in neurogenetic disorders via whole-exome sequencing of prescreened multiplex consanguineous families. Cell Reports 2015; 10: 148-61.

41. Imran Naseer M, Abdulrahman Abdulkareem A, Yousef Muthaffar O, Chaudhary AG. Exome sequencing rev- 
eled a compound heterozygous mutations in RTTN gene causing developmental delay and primary microcephaly. Saudi J Biol Sci 2021; 28: 2824-9.

42. Naseer MI, Abdulkareem AA, Muthaffar OY, et al. Whole exome sequencing identifies three novel mutations in the ASPM gene from Saudi families leading to primary microcephaly. Front Pediatr 2020; 8: 627122.

43. Algahtani $H$, Shirah $B$, Almatrafi S, Al-Qahtani $M H$, Abdulkareem AA, Naseer MI. A novel variant in CWF19L1 gene in a family with late-onset autosomal recessive cerebellar ataxia 17. Neurol Res 2021; 43: 141-7.

44. Algahtani H, Shirah B, Ullah I, Al-Qahtani MH, Abdulkareem AA, Naseer MI. Autosomal recessive cerebellar ataxia with spasticity due to a rare mutation in GBA2 gene in a large consanguineous Saudi family. Genes Dis 2021; 8: 110-4.

45. Da'as SI, Aamer W, Hasan W, et al. PGAP3 associated with hyperphosphatasia with mental retardation plays a novel role in brain morphogenesis and neuronal wiring at early development. Cells 2020; 9: E1782.

46. Kambouris M, Thevenon J, Soldatos A, et al. Biallelic SCN10A mutations in neuromuscular disease and epileptic encephalopathy. Ann Clin Transl Neurol 2017; 4: 26-35.

47. Boycott KM, Beaulieu CL, Kernohan KD, et al. Autosomal-Recessive intellectual disability with cerebellar atrophy syndrome caused by mutation of the manganese and zinc transporter gene SLC39A8. Am J Hum Genet 2015; 97: 886-93.

48. Abdel-Salam GMH, Miyake N, Abdel-Hamid MS, et al. Phenotypic and molecular insights into PQBP1-related intellectual disability. Am J Med Genet A 2018; 176: 2446-50.

49. Savasta S, Bassanese F, Buschini C, et al. Biotin-thiamine responsive encephalopathy: report of an Egyptian family with a novel SLC19A3 mutation and review of the literature. J Pediatr Genet 2019; 8: 100-8.

50. Rasheed A, Gumus E, Zaki M, et al. Bi-allelic TTC5 variants cause delayed developmental milestones and intellectual disability. J Med Genet 2021; 58: 237-46.

51. Froukh T, Nafie O, Al Hait SAS, et al. Genetic basis of neurodevelopmental disorders in 103 Jordanian families. Clin Genet 2020; 97: 621-7.

52. Froukh T. First record mutations in the genes ASPA and ARSA causing leukodystrophy in Jordan. Biomed Res Int 2019; 2019: 7235914.

53. Boschann F, Fischer-Zirnsak B, Wienker TF, et al. An intronic splice site alteration in combination with a large deletion affecting VPS13B ( $\mathrm{COH} 1)$ causes Cohen syndrome. Eur J Med Genet 2020; 63: 103973.

54. Ababneh NA, Ali D, Al-Kurdi B, et al. The utility of whole-exome sequencing in accurate diagnosis of neuromuscular disorders in consanguineous families in Jordan. Clin Chim Acta 2021: 523: 330-8.

55. Jalkh N, Corbani S, Haidar Z, et al. The added value of WES reanalysis in the field of genetic diagnosis: lessons learned from 200 exomes in the Lebanese population. BMC Med Genomics 2019; 12: 11.

56. von der Hagen M, Becker LL, Wienker TF, et al. Just expect it: compound heterozygous variants of POMT1 in a consanguineous family - the role of next generation sequencing in neuromuscular disorders. Neuropediatrics 2020; 51: 72-5.

57. Nair P, El-Bazzal L, Mansour H, et al. Further delineation of the TRAPPC6B disorder: report on a new family and review. J Pediatr Genet 2019; 8: 252-6.

58. Szklarczyk D, Franceschini A, Wyder S, et al. STRING V10: protein-protein interaction networks, integrated over the tree of life. Nucleic Acids Res 2015; 43: D447-52.
59. Alaithan MA, AbdulAzeez S, Borgio JF. A comprehensive review of the prevalence of beta globin gene variations and the co-inheritance of related gene variants in Saudi Arabians with beta-thalassemia. Saudi Med J 2018; 39: 329-35.

60. Borgio JF. Molecular nature of alpha-globin genes in the Saudi population. Saudi Med J 2015; 36: 1271-6.

61. Shamoon RP. Molecular spectrum of -thalassemia mutations in Erbil province of Iraqi Kurdistan. Mol Biol Rep 2020; 47: 6067-71.

62. Khan AM, Al-Sulaiti AM, Younes S, Yassin M, Zayed H. The spectrum of beta-thalassemia mutations in the 22 Arab countries: a systematic review. Expert Rev Hematol 2021; 14: 109-22.

63. Aldakeel SA, Ghanem NZ, Al-Amodi AM, et al. Identification of seven novel variants in the $\beta$-globin gene in transfusion-dependent and normal patients. Arch Med Sci 2020; 16: 453-9.

64. Abouelhoda M, Mohty D, Alayary I, et al. Established and candidate transthyretin amyloidosis variants identified in the Saudi population by data mining. Hum Genomics 2021; 15: 52.

65. Al-Hamed MH, Kurdi W, Alsahan N, et al. Genetic spectrum of Saudi Arabian patients with antenatal cystic kidney disease and ciliopathy phenotypes using a targeted renal gene panel. J Med Genet 2016; 53: 338-47.

66. Patel N, Khan AO, Alsahli S, et al. Genetic investigation of 93 families with microphthalmia or posterior microphthalmos. Clin Genet 2018; 93: 1210-22.

67. Shagrani M, Burkholder J, Broering D, et al. Genetic profiling of children with advanced cholestatic liver disease. Clin Genet 2017; 92: 52-61.

68. Al-Hamed MH, Sayer JA, Alsahan N, et al. Novel loss of function variants in FRAS1 AND FREM2 underlie renal agenesis in consanguineous families. J Nephrol 2021; 34: 893-900.

69. Alrakaf L, Al-Owain MA, Busehail M, et al. Further delineation of Temtamy syndrome of corpus callosum and ocular abnormalities. Am J Med Genet A 2018; 176: 715-21.

70. Altuame FD, Shamseldin HE, Albatti TH, et al. PLXNA2 as a candidate gene in patients with intellectual disability. Am J Med Genet A 2021; 185: 3859-65.

71. Anazi S, Shamseldin HE, AlNaqeb D, et al. A null mutation in TNIK defines a novel locus for intellectual disability. Hum Genet 2016; 135: 773-8.

72. Monies D, Abouelhoda M, AlSayed M, et al. The landscape of genetic diseases in Saudi Arabia based on the first 1000 diagnostic panels and exomes. Hum Genet 2017; 136: 921-39.

73. Monies D, Abouelhoda M, Assoum M, et al. Lessons learned from large-scale, first-tier clinical exome sequencing in a highly consanguineous population. Am J Hum Genet 2019; 104: 1182-201.

74. Monies D, Maddirevula S, Kurdi W, et al. Autozygosity reveals recessive mutations and novel mechanisms in dominant genes: implications in variant interpretation. Genet Med 2017; 19: 1144-50.

75. Patel N, Khan AO, Al-Saif M, et al. A novel mechanism for variable phenotypic expressivity in Mendelian diseases uncovered by an AU-rich element (ARE)-creating mutation. Genome Biol 2017; 18: 144.

76. Anazi S, Maddirevula S, Salpietro V, et al. Expanding the genetic heterogeneity of intellectual disability. Hum Genet 2017; 136: 1419-29.

77. Nair P, Lama M, El-Hayek S, et al. COQ8A and MED25 mutations in a child with intellectual disability, micro- 
cephaly, seizures, and spastic ataxia: synergistic effect of digenic variants? Mol Syndromol 2019; 9: 319-23.

78. Hebbar P, Abubaker JA, Abu-Farha M, Tuomilehto J, Al-Mulla F, Thanaraj TA. A perception on genome-wide genetic analysis of metabolic traits in Arab populations. Front Endocrinol (Lausanne) 2019; 10: 8.

79. Maddirevula S, Alzahrani F, Al-Owain M, et al. Autozygome and high throughput confirmation of disease genes candidacy. Genet Med 2019; 21: 736-42.

80. Al-Mayouf SM, Yateem M, Al-Dusery H, et al. New or vanishing frontiers: LACC1-associated juvenile arthritis. Int J Pediatr Adolesc Med 2021; 8: 44-7.

81. Wakil SM, Monies DM, Abouelhoda M, et al. Association of a mutation in LACC1 with a monogenic form of systemic juvenile idiopathic arthritis. Arthritis Rheumatol 2015; 67: 288-95.

82. Al Qahtani NH, AbdulAzeez S, Almandil NB, et al. Whole-genome sequencing reveals exonic variation of ASIC5 gene results in recurrent pregnancy loss. Front Med (Lausanne) 2021; 8: 699672.

83. Monies DM, Rahbeeni Z, Abouelhoda M, et al. Expanding Phenotypic and allelic heterogeneity of tricho-hepato-enteric syndrome. J Pediatr Gastroenterol Nutr 2015; 60: 352-6.

84. Alghamdi MA, Mulla J, Saheb Sharif-Askari N, et al. A novel biallelic STING1 gene variant causing SAVI in two siblings. Front Immunol 2020; 11: 599564.

85. Shaheen R, Anazi S, Ben-Omran T, et al. Mutations in SMG9, encoding an essential component of nonsense-mediated decay machinery, cause a multiple congenital anomaly syndrome in humans and mice. Am J Hum Genet 2016; 98: 643-52.

86. Shtir C, Aldahmesh MA, Al-Dahmash S, et al. Exome-based case-control association study using extreme phenotype design reveals novel candidates with protective effect in diabetic retinopathy. Hum Genet 2016; 135: 193-200.

87. Dasouki M, Alaiya A, ElAmin T, et al. Comprehensive multi-omics analysis of G6PC3 deficiency-related congenital neutropenia with inflammatory bowel disease. iScience 2021; 24: 102214.

88. Maddirevula S, Alsahli S, Alhabeeb L, et al. Expanding the phenome and variome of skeletal dysplasia. Genet Med 2018; 20: 1609-16.

89. Al-Dewik N, Mohd H, Al-Mureikhi M, et al. Clinical exome sequencing in 509 Middle Eastern families with suspected Mendelian diseases: The Qatari experience. Am J Med Genet A 2019; 179: 927-35.

90. Derar N, Al-Hassnan ZN, Al-Owain M, et al. De novo truncating variants in WHSC1 recapitulate the WolfHirschhorn (4p16.3 microdeletion) syndrome phenotype. Genet Med 2019; 21: 185-8.

91. Hashmi JA, Fadhli F, Almatrafi A, et al. Homozygosity mapping and whole exome sequencing provide exact diagnosis of Cohen syndrome in a Saudi family. Brain Dev 2020; 42: 587-93.

92. Al-Mousa H, Al-Dakheel G, Jabr A, et al. High incidence of severe combined immunodeficiency disease in Saudi Arabia detected through combined T cell receptor excision circle and next generation sequencing of newborn dried blood spots. Front Immunol 2018; 9: 782.

93. Bokhari HA, Shaik NA, Banaganapalli B, et al. Whole exome sequencing of a Saudi Family and systems biology analysis identifies CPED1 as a putative causative gene to celiac disease. Saudi J Biol Sci 2020; 27: 1494-502.

94. Al-Mubarak B, Abouelhoda M, Omar A, et al. Whole exome sequencing reveals inherited and de novo vari- ants in autism spectrum disorder: a trio study from Saudi families. Sci Rep 2017; 7: 5679.

95. Massadeh S, Albeladi M, Albesher N, et al. Novel autosomal recessive splice-altering variant in PRKD1 is associated with congenital heart disease. Genes (Basel) 2021; 12: 612 .

96. Ciliopathy Working Group; Shaheen R, Szymanska K, Basu B, et al. Characterizing the morbid genome of ciliopathies. Genome Biol 2016; 17: 242.

97. Bohlega SA, Al-Mubarak BR, Alyemni EA, et al. Clinical heterogeneity of PLA2G6-related parkinsonism: analysis of two Saudi families. BMC Res Notes 2016; 9: 295.

98. Patel N, Aldahmesh MA, Alkuraya $\mathrm{H}$, et al. Expanding the clinical, allelic, and locus heterogeneity of retinal dystrophies. Genet Med 2016; 18: 554-62

99. Azab B, Barham R, Ali D, et al. Novel CERKL variant in consanguineous Jordanian pedigrees with inherited retinal dystrophies. Can J Ophthalmol 2019; 54: 51-9.

100. Abu-Ameerh M, Mohammad H, Dardas Z, et al. Extending the spectrum of CLRN1- and ABCA4-associated inherited retinal dystrophies caused by novel and recurrent variants using exome sequencing. Mol Genet Genomic Med 2020; 8: e1123.

101. Bogari NM, Amin AA, Rayes HH, et al. Next generation exome sequencing of pediatric asthma identifies rare and novel variants in candidate genes. Dis Markers 2021; 2021: 8884229

102. Aloraini T, Alsubaie L, Alasker S, et al. The rate of secondary genomic findings in the Saudi population. Am J Med Genet A 2022; 188: 83-8.

103. Ahmed ABM, Alsaleem BMR. Enteroendocrine dysfunction in two Saudi sisters. Case Rep Gastroenterol 2021: 15: $290-5$.

104. Alsaleem BM, Hasosah M, Ahmed ABM, et al. Tricho-hepato-enteric syndrome: retrospective multicenter experience in Saudi Arabia. Saudi J Gastroenterol 2022; 28: 135-42.

105. Al-Khawaga S, Mohammed I, Saraswathi S, et al. The Clinical and genetic characteristics of permanent neonatal diabetes (PNDM) in the state of Qatar. Mol Genet Genomic Med 2019; 7: e00753.

106. Saadah OI, Banaganapalli B, Kamal NM, et al. Identification of a rare exon 19 skipping mutation in ALMS1 gene in Alström syndrome patients from two unrelated Saudi families. Front Pediatr 2021; 9: 652011.

107. Bdier AY, Al-Qahtani FA, Kumar Verma P, et al. A novel homozygous ALMS1 protein truncation mutation (c.2938dupA) revealed variable clinical expression among Saudi Alström syndrome patients. Arch Med Sci 2020; doi:10.5114/aoms.2020.100635.

108. Patel N, Alkuraya H, Alzahrani SS, et al. Mutations in known disease genes account for the majority of autosomal recessive retinal dystrophies. Clin Genet 2018; 94: 554-63.

109. Monies D, Anabrees J, Ibrahim N, et al. Identification of a novel lethal form of autosomal recessive ichthyosis caused by UDP-glucose ceramide glucosyltransferase deficiency. Clin Genet 2018; 93: 1252-3.

110. Shaheen R, Al Tala S, Ewida N, Abouelhoda M, Alkuraya FS. Epileptic encephalopathy with continuous spike-and-wave during sleep maps to a homozygous truncating mutation in AMPA receptor component FRRS1L. Clin Genet 2016; 90: 282-3.

111. Yemni EA, Monies D, Alkhairallah T, et al. Integrated analysis of whole exome sequencing and copy number evaluation in Parkinson's disease. Sci Rep 2019; 9: 3344.

112. Elfatih A, Mifsud B, Syed N, Badii R, Mbarek H, Abbaszadeh F. The Qatar Genome Program Research 
Consortium; Estivill X. Actionable genomic variants in 6045 participants from the Qatar Genome Program. Hum Mutat 2021; doi: 10.1002/humu.24278.

113. Younes N, Syed N, Yadav SK, Haris M, Abdallah AM, Abu-Madi M. A whole-genome sequencing association study of low bone mineral density identifies new susceptibility loci in the phase I Qatar Biobank cohort. J Pers Med 2021; 11: 34.

114. Umar M, Megarbane A, Shan J, et al. Genome sequencing unveils mutational landscape of the familial Mediterranean fever: potential implications of IL33/ST2 signalling. J Cell Mol Med 2020; 24: 11294-306.

115. Daga A, Majmundar AJ, Braun DA, et al. Whole exome sequencing frequently detects a monogenic cause in early onset nephrolithiasis and nephrocalcinosis. Kidney Int 2018; 93: 204-13.

116. El Hawary R, Meshaal S, Mauracher AA, et al. Whole-exome sequencing of $\mathrm{T}-\mathrm{B}+$ severe combined immunodeficiency in Egyptian infants, JAK3 predominance and novel variants. Clin Exp Immunol 2021; 203: 448-57.

117. Ibrahim AZ, Thirumal Kumar D, Abunada T, et al. Investigating the structural impacts of a novel missense variant identified with whole exome sequencing in an Egyptian patient with propionic acidemia. Mol Genet Metab Rep 2020; 25: 100645.

118. Zaki MS, Selim L, El-Bassyouni HT, et al. Molybdenum cofactor and isolated sulphite oxidase deficiencies: clinical and molecular spectrum among Egyptian patients. Eur J Paediatr Neurol 2016; 20: 714-22.

119. McClain L, Mansour H, Ibrahim I, et al. Age Dependent association of inbreeding with risk for schizophrenia in Egypt. Schizophr Res 2020; 216: 450-9.

120. Sandhya P, Vellarikkal SK, Nair A, et al. Egyptian tale from India: application of whole-exome sequencing in diagnosis of atypical familial Mediterranean fever. Int J Rheum Dis 2017; 20: 1770-5.

121. Amr K, Pawlikowska P, Aoufouchi S, Rosselli F, El-Kamah $G$. Whole exome sequencing identifies a new mutation in the SLC19A2 gene leading to thiamine-responsive megaloblastic anemia in an Egyptian family. Mol Genet Genomic Med 2019; 7: e00777.

122. Megahed H, Nicouleau M, Barcia G, et al. Utility of whole exome sequencing for the early diagnosis of pediatric-onset cerebellar atrophy associated with developmental delay in an inbred population. Orphanet J Rare Dis 2016; 11: 57.

123. Habibi I, Youssef M, Marzouk E, et al. Mutations in VSX2, SOX2, and FOXE3 Identified in patients with micro-/anophthalmia. Adv Exp Med Biol 2019; 1185: 221-6.

124. Meshaal SS, El Hawary RE, Abd Elaziz DS, et al. Phenotypical heterogeneity in RAG-deficient patients from a highly consanguineous population. Clin Exp Immunol 2019; 195: 202-12.

125. Nabil A, El Shafei S, El Shakankiri NM, et al. A familial PLCB4 mutation causing auriculocondylar syndrome 2 with variable severity. Eur J Med Genet 2020; 63: 103917.

126. Ahmed HA, El-Kamah GY, Rabie E, et al. Gene mutations of the three ectodysplasin pathway key players (EDA, EDAR, and EDARADD) account for more than $60 \%$ of Egyptian ectodermal dysplasia: a report of seven novel mutations. Genes (Basel) 2021; 12: 1389.

127. Zaki M, Thoenes M, Kawalia A, et al. Recurrent and Prolonged infections in a child with a homozygous IFIH1 nonsense mutation. Front Genet 2017; 8: 130.
128. Khairat R, Elhossini R, Sobreira N, et al. Expansion of the phenotypic and mutational spectrum of carpenter syndrome. Eur J Med Genet 2021; 65: 104377.

129. Mazen I, Mekkawy M, Kamel A, et al. Advances in genomic diagnosis of a large cohort of Egyptian patients with disorders of sex development. Am J Med Genet A 2021; 185: 1666-77.

130. Nabhan MM, Abdelaziz $\mathrm{H}, \mathrm{Xu} \mathrm{Y}$, et al. Case report: whole-exome analysis of a child with polycystic kidney disease and ventriculomegaly. Genet Mol Res 2015; 14: 3618-24.

131. Duan R, Saadi NW, Grochowski CM, et al. A novel homozygous SLC13A5 whole-gene deletion generated by alu/alu-mediated rearrangement in an Iraqi family with epileptic encephalopathy. Am J Med Genet A 2021; 185: 1972-80.

132. Gilani N, Razmara E, Ozaslan M, et al. A novel deletion variant in CLN3 with highly variable expressivity is responsible for juvenile neuronal ceroid lipofuscinoses. Acta Neurol Belg 2021; 121: 737-48.

133. Hamamy H, Makrythanasis P, Al-Allawi N, Muhsin AA Antonarakis SE. Recessive thrombocytopenia likely due to a homozygous pathogenic variant in the FYB gene: case report. BMC Med Genet 2014; 15: 135.

134. Vandervore LV, Schot R, Milanese $C$, et al. TMX2 is a crucial regulator of cellular redox state, and its dysfunction causes severe brain developmental abnormalities. Am J Hum Genet 2019; 105: 1126-47.

135. Beck BB, Phillips JB, Bartram MP, et al. Mutation of POC1B in a severe syndromic retinal ciliopathy. Hum Mutat 2014; 35: 1153-62.

136. Pode-Shakked B, Vivante A, Barel O, et al. Progressive pseudorheumatoid dysplasia resolved by whole exome sequencing: a novel mutation in WISP3 and review of the literature. BMC Med Genet 2019; 20: 53.

137. Al-Kzayer LFY, Al-Aradi HMH, Shigemura T, et al. DOCK8 Mutation diagnosed using whole-exome sequencing of the dried blood spot-derived DNA: a case report of an Iraqi girl diagnosed in Japan. BMC Med Genet 2019; 20: 114.

138. Meng L, Isohanni P, Shao Y, et al. MED27 variants cause developmental delay, dystonia, and cerebellar hypoplasia. Ann Neurol 2021; 89: 828-33.

139. Bastaki F, Mohamed M, Nair P, et al. A novel SOX18 mutation uncovered in Jordanian patient with hypotrichosis-lymphedema-telangiectasia syndrome by whole exome sequencing. Mol Cell Probes 2016; 30: 18-21.

140. Altamimi E, Khanfar M, Rabab'h O, et al. Effect of genetic testing on diagnosing gastrointestinal pediatric patients with previously undiagnosed diseases. Appl Clin Genet 2020; 13: 221-31.

141. Al-Bdour M, Pauleck S, Dardas Z, et al. Clinical heterogeneity in retinitis pigmentosa caused by variants in RP1 and RLBP1 in five extended consanguineous pedigrees. Mol Vis 2020; 26: 445-58.

142. Dardas Z, Swedan S, Al-Sheikh Qassem A, Azab B. The impact of exome sequencing on the diagnostic yield of muscular dystrophies in consanguineous families. Eur J Med Genet 2020; 63: 103845.

143. Froukh T, Hawwari A, Al Zubi K. Whole exome sequencing highlights variants in association with keratoconus in Jordanian families. BMC Med Genet 2020; 21: 177.

144. Mansour H, Sabbagh S, Bizzari S, et al. The Lebanese allele in the PET100 gene: report on two new families with cytochrome c oxidase deficiency. J Pediatr Genet 2019; 8: 172-8.

145. Nemer G, El-Hachem N, Eid E, et al. A novel TRAF3IP2 Variant causing familial scarring alopecia with mixed 
features of discoid lupus erythematosus and folliculitis decalvans. Clin Genet 2020; 98: 116-25.

146. Jaffal L, Joumaa WH, Assi A, et al. Next generation sequencing identifies five novel mutations in Lebanese patients with Bardet-Biedl and Usher syndromes. Genes (Basel) 2019; 10: E1047.

147. Nair P, Sabbagh S, Bizzari S, et al. Report of a second Lebanese family with Basel-Vanagaite-Smirin-Yosef syndrome: possible founder mutation. Mol Syndromol 2019; 10: 219-22.

148. Younes S, Ibrahim A, Al-Jurf R, Zayed H. Genetic polymorphisms associated with obesity in the Arab world: a systematic review. Int J Obes 2021; 45: 1899-913.

149. Zayani N, Omezzine A, Boumaiza I, et al. Association of ADIPOQ, leptin, LEPR, and resistin polymorphisms with obesity parameters in Hammam Sousse Sahloul Heart Study. J Clin Lab Anal 2017; 31: e22148.

150. Mohammed A, Al-Thuwaini T, Al-Shuhaib M. Single nucleotide polymorphism Rs7908486 of the TCF7L2 gene is highly associated with obesity in the Iraqi population. Arch Biol Sci (Beogr) 2021; 73: 39-45.

151. Al-Mousa H, Abouelhoda M, Monies DM, et al. Unbiased targeted next-generation sequencing molecular approach for primary immunodeficiency diseases. J Allergy Clin Immunol 2016; 137: 1780-7.

152. Al-Mubarak BR, Omar A, Baz B, et al. Whole exome sequencing in $A D H D$ trios from single and multi-incident families implicates new candidate genes and highlights polygenic transmission. Eur J Hum Genet 2020; 28: 1098-110.

153. Shaheen R, Maddirevula S, Ewida N, et al. Genomic and phenotypic delineation of congenital microcephaly. Genet Med 2019; 21: 545-52.

154. Owaidah T, Saleh M, Baz B, et al. Molecular yield of targeted sequencing for Glanzmann thrombasthenia patients. NPJ Genom Med 2019; 4: 4.

155. Alshenaifi J, Ewida N, Anazi S, et al. The many faces of peroxisomal disorders: lessons from a large Arab cohort. Clin Genet 2019; 95: 310-9.

156. Alazami AM, Al-Helale M, Alhissi S, et al. Novel CARMIL2 mutations in patients with variable clinical dermatitis, infections, and combined immunodeficiency. Front Immunol 2018; 9: 203.

157. Aljasmi FA, Vijayan R, Sudalaimuthuasari N, et al. Genomic landscape of the mitochondrial genome in the United Arab Emirates native population. Genes (Basel) 2020; 11: E876.

158. Dashti M, Alsaleh H, Eaaswarkhanth M, et al. Delineation of mitochondrial DNA variants from exome sequencing data and association of haplogroups with obesity in Kuwait. Front Genet 2021; 12: 626260.

159. Dashti M, Alsaleh H, Rodriguez-Flores JL, Eaaswarkhanth M, Al-Mulla F, Thanaraj TA. Mitochondrial haplogroup J associated with higher risk of obesity in the Qatari population. Sci Rep 2021; 11: 1091. 